\title{
Cyclostreptin (FR182877), an Antitumor Tubulin-Polymerizing Agent Deficient in Enhancing Tubulin Assembly Despite Its High Affinity for the Taxoid Site
}

\author{
Michael C. Edler, ${ }^{\ddagger}$ Rubén M. Buey, ${ }^{\S}$ Rick Gussio," Adam I. Marcus, ${ }^{\perp}$ Christopher D. Vanderwal, ${ }^{@}$ \\ Erik J. Sorensen, ${ }^{@, \# ~ J . ~ F e r n a n d o ~ D i ́ a z, ~}{ }^{\S}$ Paraskevi Giannakakou, ${ }^{\perp}$ and Ernest Hamel*,* \\ Screening Technologies Branch, Developmental Therapeutics Program, Division of Cancer Treatment and Diagnosis, \\ National Cancer Institute at Frederick, National Institutes of Health, Frederick, Maryland 21702, Centro de Investigaciones \\ Biológicas, Consejo Superior de Investigaciones Cientificas, 28040 Madrid, Spain, Information Technology Branch, \\ Developmental Therapeutics Program, Division of Cancer Treatment and Diagnosis, National Cancer Institute at Frederick, \\ National Institutes of Health, Frederick, Maryland 21702, Winship Cancer Institute, Emory University School of Medicine, \\ Atlanta, Georgia 30322, and Department of Chemistry, The Scripps Research Institute and \\ University of California at San Diego, La Jolla, California 92037
}

Received April 11, 2005; Revised Manuscript Received June 16, 2005

\begin{abstract}
Cyclostreptin (FR182877), a bacterial natural product, was reported to have weak paclitaxellike activity with tubulin but antitumor activity in vivo. We used synthetic cyclostreptin in studies of its mechanism of action. Although less potent than paclitaxel in several human cancer cell lines, cyclostreptin was active against cells resistant to paclitaxel and epothilone A. At equitoxic concentrations with paclitaxel, cyclostreptin was more effective in arresting MCF-7 cells in mitosis and equivalent in bundling microtubules in $\mathrm{PtK}_{2}$ cells. Tubulin assembly with paclitaxel occurs at low temperatures and in the absence of GTP or microtubule-associated proteins (MAPs). Brisk assembly with cyclostreptin required MAPs, GTP, and higher reaction temperatures. On the basis of turbidimetry, cyclostreptin-induced microtubules were more stable in the cold than the paclitaxel-induced polymer. Moreover, at $37{ }^{\circ} \mathrm{C}$ cyclostreptin was a strong competitive inhibitor of the binding of radiolabeled paclitaxel to tubulin polymer, with an apparent $K_{\mathrm{i}}$ value of $88 \mathrm{nM}$. Competition studies versus a fluorescent taxoid across a temperature range, in comparison with paclitaxel and docetaxel, showed that only the binding of cyclostreptin to microtubules was markedly reduced at $4{ }^{\circ} \mathrm{C}$ versus temperatures over $30{ }^{\circ} \mathrm{C}$. The binding of cyclostreptin to microtubules was characterized by a relatively greater endothermic and entropic profile as compared with those of the taxoid binding reactions, which are characterized more by exothermic and enthalpic interactions. Molecular modeling showed that cyclostreptin formed a pharmacophore with taxoids but formed hydrogen bonds only with the S9-S10 and M loops in the taxoid site. Initial studies also indicate that, relative to paclitaxel, cyclostreptin is more deficient in nucleation than elongation of polymer.
\end{abstract}

Many small molecules have been found that interact with tubulin, arrest cells in mitosis, and alter the dynamic properties of microtubules, even at low concentrations where little change in microtubule mass occurs (1). A subset of these compounds, at higher concentrations, promotes the excessive growth of hyperstable microtubules. The lead compounds

$\doteqdot$ This work was supported in part by Grants BIO2001-1725 from McyT, 07B/0026/2002 from Comunidad de Madrid, and BFU20040358/BMC from MEC. R.M.B. was supported by a MECD FPU predoctoral fellowship.

* To whom correspondence should be addressed: Building 469, Room 104, NCI-Frederick, Frederick, MD 21702. Phone: (301) 8461678. Fax: (301) 846-6014. E-mail: hamele@mail.nih.gov.

Screening Technologies Branch, Developmental Therapeutics Program, Division of Cancer Treatment and Diagnosis, National Cancer Institute at Frederick, National Institutes of Health.

$\S$ Consejo Superior de Investigaciones Cientificas.

"Information Technology Branch, Developmental Therapeutics Program, Division of Cancer Treatment and Diagnosis, National Cancer Institute at Frederick, National Institutes of Health.

${ }^{\perp}$ Emory University School of Medicine.

@ The Scripps Research Institute and University of California at San Diego.

\# Current address: Department of Chemistry, Princeton University, Princeton, NJ 08544. with this mechanism of action have all been obtained from natural sources, and most are highly cytotoxic $(2-12)$. The clinical success of paclitaxel (13) and docetaxel (14) (structures in Figure 1) has prompted the extensive investigation of this class of antimitotic compounds.

Of all the natural products reported to have a taxoidmimetic mechanism of action, the least characterized is FR $182877^{1}(8,9)$ (structure in Figure 1), which we propose naming cyclostreptin ("cyclo" indicating its multiple-fused ring structure and "streptin" after the organism of origin). Cyclostreptin was first recovered from a fermentation broth of the bacterium Streptomyces sp. No. 9885 and shown to have an apparently weak paclitaxel-like activity, particularly in biochemical assays (9). In vivo, however, cyclostreptin was active against two murine tumors (8).

\footnotetext{
${ }^{1}$ The compound was originally named WS $9885 \mathrm{~B}$ and assigned the opposite configuration compared to that shown in Figure $1(10,47)$. This enantiomer, when synthesized, was dextrorotatory rather than levorotatory like the natural product (15), and it was inactive with tubulin (unpublished data). Further analysis of the natural product led to revision of the originally proposed structure to that shown in Figure $1(10)$.
} 


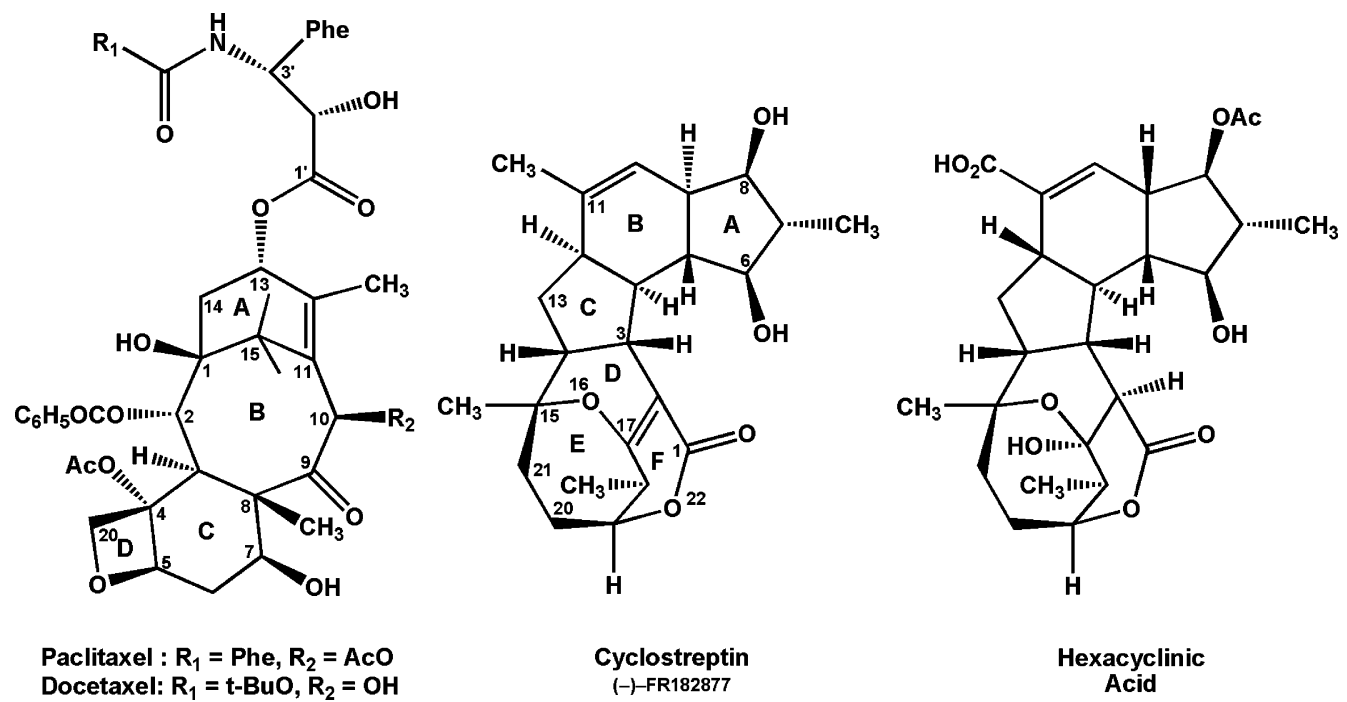

FIGURE 1: Structures of paclitaxel, docetaxel, cyclostreptin [(-)-FR182877], and hexacyclinic acid.

The promising anticancer activity and the successful synthesis of cyclostreptin (15-17) led us to undertake the studies presented here. At the cellular level, we found cyclostreptin to be 7-12 times less effective than paclitaxel in inhibiting the growth of two human cancer cell lines, but $\sim 25$ times more inhibitory than paclitaxel in $\mathrm{PtK}_{2}$ cells. In the latter line, cyclostreptin bundled microtubules in a way that made them indistinguishable from those bundled in the presence of paclitaxel. Cyclostreptin also caused an increase in the number of mitotic cells. Ovarian carcinoma cells resistant to either paclitaxel or epothilone $\mathrm{A}$, based on mutations in the M40 $\beta$-tubulin gene $(18,19)$, retained sensitivity to cyclostreptin.

In biochemical studies, we initially confirmed the apparently feeble activity of cyclostreptin in promoting microtubule formation. In fact, cyclostreptin was significantly less active than sarcodictyins A and B, which both have little activity in inhibiting cell growth (20). Surprisingly, cyclostreptin potently inhibited the binding of $\left[{ }^{3} \mathrm{H}\right]$ paclitaxel ${ }^{2}$ to tubulin polymer; on the other hand, the sarcodictyins are weak inhibitors. Inhibition by cyclostreptin displayed a competitive pattern. We further explored the interaction of cyclostreptin with tubulin polymer by examining its effects on the binding of the fluorescent paclitaxel analogue Flutax-2 to glutaraldehyde-fixed microtubules. Compared with paclitaxel and docetaxel, cyclostreptin had a greatly decreased affinity for polymer at $4{ }^{\circ} \mathrm{C}$ but not at $35^{\circ} \mathrm{C}$. The decreased affinity of cyclostreptin for microtubules in the cold, together with its low activity in inducing assembly, suggests that the compound may be relatively deficient in the nucleation step as compared with the elongation step in microtubule assembly.

Molecular modeling showed that cyclostreptin superimposed well on paclitaxel in the electron crystallographic model of tubulin in protofilaments $(19,21)$. Cyclostreptin,

${ }^{2}$ Abbreviations: $\left[{ }^{3} \mathrm{H}\right]$ paclitaxel, $\left[3^{\prime \prime}-{ }^{3} \mathrm{H}\right]$ paclitaxel; Flutax-2, 7-O[ $N$-(2,7-difluoro-4'-fluoresceincarbonyl)-L-alanyl]paclitaxel; H-bond, hydrogen bond; DMSO, dimethyl sulfoxide; MAPs, microtubuleassociated proteins; ddGTP, 2',3'-dideoxyguanosine $5^{\prime}$-triphosphate; Mes, 4-morpholineethanesulfonate; PBS, phosphate-buffered saline; DAPI, 4',6-diamidino-2-phenylindole; FITC, fluorescein isothiocyanate; SD, standard deviation; SE, standard error; HCM, hexacyclinic acid monohydrate. however, formed significantly fewer H-bonds with amino acid residues in the taxoid binding site. This was consistent with its unusual binding properties.

\section{EXPERIMENTAL PROCEDURES}

Materials. Cyclostreptin was synthesized as described previously (16). Epothilone A, docetaxel, discodermolide, and sarcodictyins A and B were generous gifts of Merck Research Laboratories, D. G. I. Kingston (Virginia Polytechnic and State University) and Aventis Pharmaceuticals, R. E. Longley (Harbor Branch Oceanographic Institution), and K. C. Nicolaou (Scripps Research Institute), respectively. Paclitaxel and $\left[{ }^{3} \mathrm{H}\right]$ paclitaxel $(19.3 \mathrm{mCi} / \mathrm{mmol})$ were obtained from the Drug Synthesis and Chemistry Branch of the National Cancer Institute. Compounds were dissolved in DMSO, and control samples contained equal amounts of solvent. Heat-treated MAPs and electrophoretically homogeneous tubulin (used in the assembly, $\left[{ }^{3} \mathrm{H}\right]$ paclitaxel binding, and morphological studies) were prepared from bovine brains (22). Unbound nucleotide was removed from this tubulin by gel filtration chromatography (23). Flutax-2 was synthesized (24), and the tubulin used in Flutax-2 binding studies was prepared from calf brains as described previously (25). GTP, from Sigma, and ddGTP, from Pharmacia, were repurified by anion exchange chromatography on DEAE-cellulose, and the samples were $>99 \%$ pure at the time of isolation. Potorus tridactylis kidney epithelial $\left(\mathrm{PtK}_{2}\right)$ cells were from American Type Culture Collection. FITC-labeled monoclonal anti- $\beta$ tubulin clone tub 2.1 antibody was from Sigma. The human breast carcinoma MCF-7 cell line was provided by the National Cancer Institute drug screening program. The human ovarian carcinoma line 1A9, a clone of line A2780 (26), was used to generate both the paclitaxel-resistant and epothilone-resistant lines $(18,19)$.

Inhibition of Tumor Cell Growth. The ovarian carcinoma cell lines were continuously maintained in RPMI-1640 medium containing $10 \%$ fetal calf serum, $12 \mu \mathrm{g} / \mathrm{mL}$ gentamicin sulfate, and $2 \mathrm{mM}$ L-glutamine. Paclitaxel- and epothilone-resistant cell lines were maintained as described previously $(18,19)$. MCF-7 cells were maintained in RPMI1640 medium containing 5\% fetal bovine serum and $2 \mathrm{mM}$ L-glutamine. Following compound addition, ovarian cells 
were grown for $96 \mathrm{~h}$ and the MCF-7 cells for $48 \mathrm{~h}$ in 96well plates before fixation and measurement of the level of cellular protein with sulforhodamine B (27).

Mitotic Index. MCF-7 cells were seeded at a density of $\sim 12500$ cells/well into individual compartments of a Chamber Coverglass System from Nunc-Nalgene and allowed to adhere overnight. Compounds, as indicated, were added [final DMSO concentration of $0.5 \%(\mathrm{v} / \mathrm{v})]$, and cells were incubated for $18 \mathrm{~h}$ at $37{ }^{\circ} \mathrm{C}$. Medium was removed, and cells were fixed with $4 \%$ paraformaldehyde in PBS for $45 \mathrm{~min}$. Cells were washed twice with PBS and stained with DAPI for 30-60 min at room temperature in the dark. Slides were washed with PBS and water and mounted on a slide cover with Antifade Mounting Solution from Molecular Probes. Slides were examined with a Nikon Eclipse E800 microscope equipped with epifluorescence and an appropriate filter. Cells with condensed chromosomes were counted as mitotic cells. Five hundred cells were counted for each reaction condition that was tested.

Direct Immunofluorescence. For immunofluorescence studies, $\mathrm{PtK}_{2}$ cells were grown to confluence, disrupted by trypsinization, and seeded at a density of $\sim 35000$ cells/well into individual compartments of a Chambered Coverglass System and allowed to adhere overnight. Compounds, as indicated, were added (final DMSO concentration of $1 \%$ ), and cells were left for $18 \mathrm{~h}$ at $37^{\circ} \mathrm{C}$. Cells were washed twice with PBS, fixed with methanol at $-20^{\circ} \mathrm{C}$ for $10 \mathrm{~min}$, and permeabilized with $-20^{\circ} \mathrm{C}$ acetone for $1 \mathrm{~min}$. The cover glass was washed twice with PBS, and $200 \mu \mathrm{L}$ of DAPI at $1.0 \mu \mathrm{g} / \mathrm{mL}$ and the FITC-conjugated anti- $\beta$-tubulin monoclonal antibody, diluted 1:25 with PBS, were added to the cover glass, which was left for $1-3 \mathrm{~h}$ at room temperature in the dark. The cover glass was washed three times with PBS, mounted on a slide with Antifade Mounting Solution, and examined with the Eclipse E800 microscope. Images were captured with a Spot digital camera, model 2.3.0, using version 3.0.2 software, from Diagnostic Instruments.

Tubulin Assembly. Polymerization was followed turbidimetrically in Gilford model 250 recording spectrophotometers, as described previously (20), except that each compound was added to reaction mixtures on ice prior to addition to cuvettes held at $0{ }^{\circ} \mathrm{C}$, unless indicated otherwise. Baseline readings were taken at $0{ }^{\circ} \mathrm{C}$, and the temperature was increased in steps as indicated.

Electron Microscopy. Polymerization reactions were performed at $30^{\circ} \mathrm{C}$ for $30 \mathrm{~min}$, and aliquots were removed from the samples and placed on 200-mesh carbon-coated, Formvar-treated, copper grids and stained dropwise with $1.0 \%$ $(w / v)$ uranyl acetate. Samples were also taken from reaction mixtures for morphological examination $30 \mathrm{~min}$ after the temperature was lowered to $0{ }^{\circ} \mathrm{C}$. Aliquots from reaction mixtures used to determine microtubule lengths were first diluted into a prewarmed $50 \%$ sucrose $/ 0.1 \mathrm{M}$ Mes mixture (pH 6.9 with $\mathrm{NaOH}$ in a $1.0 \mathrm{M}$ stock solution) (28). Grids were examined in a Zeiss model 10CA electron microscope and photographed for microtubule measurement and morphological evaluation. Microtubule lengths were measured using ImageTool version 3.00, obtained from the University of Texas Health Science Center in San Antonio website.

Inhibition of Binding of $\left[{ }^{3} \mathrm{H}\right]$ Paclitaxel to Polymer. The method for assessing inhibition of binding of $\left[{ }^{3} \mathrm{H}\right]$ paclitaxel to tubulin polymer was described previously (20). Microtu- bule polymer was initially assembled for $30 \mathrm{~min}$ at $37^{\circ} \mathrm{C}$ in a reaction mixture containing $2.5 \mu \mathrm{M}$ tubulin, $25 \mu \mathrm{M}$ ddGTP, and $0.75 \mathrm{M}$ monosodium glutamate $(\mathrm{pH} 6.6$ with $\mathrm{HCl}$ in a 2.0 M stock solution) ( $\sim 90 \%$ of the tubulin is polymerized under these conditions). Mixtures of $\left[{ }^{3} \mathrm{H}\right]$ paclitaxel and inhibitors at the indicated concentrations were incubated with the preformed microtubules (final concentration of tubulin of $2 \mu \mathrm{M}$ and final concentration of DMSO of $4 \%$ ) for an additional $30 \mathrm{~min}$ at $37^{\circ} \mathrm{C}$. Reaction mixtures (final volume of $0.25 \mathrm{~mL})$ were centrifuged at room temperature $\left(\sim 22^{\circ} \mathrm{C}\right)$ for $20 \mathrm{~min}$ at $14000 \mathrm{rpm}$ in an Eppendorf desktop centrifuge to pellet the microtubules, and $0.10 \mathrm{~mL}$ of each supernatant was counted. The amount of bound paclitaxel was calculated by subtracting the amount of supernatant paclitaxel from the total amount of paclitaxel.

Analysis of the $\left[{ }^{3} H\right]$ Paclitaxel Binding Data. It is not uncommon to analyze stoichiometric binding data by enzyme kinetic methods (29). These include Lineweaver-Burk or Hanes analysis, to determine the type of inhibition, and Dixon analysis for determination of apparent $K_{\mathrm{i}}$ values. Although these types of analyses indicated cyclostreptin was a competitive inhibitor of binding of paclitaxel to tubulin polymer (see below), we were uncomfortable substituting the percent saturation of binding sites at or near equilibrium for initial velocity and using total "substrate" (paclitaxel) and inhibitor concentrations close to the tubulin concentration in an analysis derived under conditions where substrate and inhibitor were in large excess over enzyme. We were nonetheless able to derive an analytical formula at equilibrium equivalent to the Hanes format, where free substrate concentration per substrate bound is plotted versus free substrate concentration.

At equilibrium with two ligands in the reaction mixture, where $\mathrm{M}$ is the microtubule binding site, $\mathrm{S}$ is the substrate ligand (paclitaxel), and $\mathrm{i}$ is the inhibitor ligand (cyclostreptin):

$$
\mathrm{M}+\mathrm{S} \leftrightarrow \mathrm{M} \cdot \mathrm{S} \text { and } \mathrm{M}+\mathrm{i} \leftrightarrow \mathrm{M} \cdot \mathrm{i}
$$

Therefore

$$
K_{\mathrm{d}}=[\mathrm{M}][\mathrm{S}] /[\mathrm{M} \cdot \mathrm{S}] \text { and } K_{\mathrm{i}}=[\mathrm{M}][\mathrm{i}] /[\mathrm{M} \cdot \mathrm{i}]
$$

where $[\mathrm{M}],[\mathrm{S}]$, and [i] represent the concentrations of unoccupied microtubule binding sites, free substrate, and free inhibitor, respectively, and $[\mathrm{M} \cdot \mathrm{S}]$ and $[\mathrm{M} \cdot \mathrm{i}]$ the concentrations of occupied sites.

The fractional saturation $v$ of the microtubule sites with paclitaxel in the presence of both paclitaxel and cyclostreptin will be

$$
v=[\mathrm{M} \cdot \mathrm{S}] /([\mathrm{M}]+[\mathrm{M} \cdot \mathrm{S}]+[\mathrm{M} \cdot \mathrm{i}])
$$

Substituting yields

$$
v=\left([\mathrm{M}][\mathrm{S}] / K_{\mathrm{d}}\right) /\left([\mathrm{M}]+[\mathrm{M}][\mathrm{S}] / K_{\mathrm{d}}+[\mathrm{M}][\mathrm{i}] / K_{\mathrm{i}}\right)
$$

Dividing by $[\mathrm{M}]$ yields

$$
v=\left([\mathrm{S}] / K_{\mathrm{d}}\right) /\left(1+[\mathrm{S}] / K_{\mathrm{d}}+[\mathrm{i}] / K_{\mathrm{i}}\right)
$$

Dividing by $[\mathrm{S}] / K_{\mathrm{d}}$ yields

$$
v=1 /\left(1+K_{\mathrm{d}} /[\mathrm{S}]+[\mathrm{i}] K_{\mathrm{d}} / K_{\mathrm{i}}[\mathrm{S}]\right)=1 /\left[1+\left(K_{\mathrm{d}} /[\mathrm{S}]\right)(1+\right.
$$


Which inverts to

$$
1 / v=1+\left(K_{\mathrm{d}} /[\mathrm{S}]\right)\left(1+[\mathrm{i}] / K_{\mathrm{i}}\right)
$$

Multiplying by [S] yields an equation formally equivalent to the Hanes equation:

$$
[\mathrm{S}] / v=K_{\mathrm{d}}\left(1+[\mathrm{i}] / K_{\mathrm{i}}\right)+[\mathrm{S}]
$$

and plotting $[\mathrm{S}] / v$ on the ordinate versus $[\mathrm{S}]$ on the abscissa should yield a series of parallel lines with a slope of 1 and intercepting the abscissa at $-K_{\mathrm{d}}$ in the absence of inhibitor and at $-K_{\mathrm{d}}\left(1+[\mathrm{i}] / K_{\mathrm{i}}\right)$ at each concentration of inhibitor.

The free paclitaxel concentrations were readily obtained from the experimental data (radiolabel in the supernatants) and the fractional saturation $v$ as described above (free subtracted from total paclitaxel concentration). The free cyclostreptin concentrations were assumed to be approximately equivalent to the total amount of cyclostreptin minus the amount of paclitaxel displaced by the cyclostreptin, and these values were similar for all samples with the same total cyclostreptin concentration $(0.3 \mu \mathrm{M}$ free cyclostreptin with $0.5 \mu \mathrm{M}$ total, $0.5 \mu \mathrm{M}$ free cyclostreptin with $0.75 \mu \mathrm{M}$ total, and $0.7 \mu \mathrm{M}$ free cyclostreptin with $1.0 \mu \mathrm{M}$ total). The apparent $K_{\mathrm{d}}$ value for paclitaxel and the apparent $K_{\mathrm{i}}$ value for cyclostreptin were obtained from the abscissa intercepts (see above).

Inhibition of Binding of Flutax-2 to Polymer. Accurate binding constants for cyclostreptin at various temperatures were obtained by assessing its competition with Flutax-2, a fluorescent taxoid probe of the paclitaxel binding site, in binding to glutaraldehyde-fixed microtubules $(30,31)$. The displacement isotherms of the ligand were determined in several independent experiments by measuring fluorescence anisotropy with a fluorescence polarization microplate reader at temperatures from 26 to $42{ }^{\circ} \mathrm{C}$, as described previously $(32-34)$. The binding constants of the reference ligand Flutax-2 were previously determined $(30,34)$. Measurements at $4{ }^{\circ} \mathrm{C}$ were conducted on a Spex FluoroLog-3 spectrofluorimeter. The resulting reference constant (apparent $K_{\mathrm{a}}$ value) for Flutax-2 at this temperature was $[1.67 \pm 0.06(\mathrm{SE})]$ $\times 10^{8} \mathrm{M}^{-1}$. Competitor concentrations up to $200 \mu \mathrm{M}, 50$ $\mathrm{nM}$ Flutax-2, and $50 \mathrm{nM}$ (in terms of potential taxoid binding sites) cross-linked microtubules were used. The experimental data were best fitted by least-squares to the equilibrium binding constant values of the reference ligand, using EQUIGRA version 5 (available from J. F. Díaz). The thermodynamic parameters were calculated from the binding equilibrium constants using the van't Hoff and Gibbs equations.

Model of Cyclostreptin As Determined by Molecular Modeling. Our initial modeling of cyclostreptin began with the X-ray crystallographic coordinates of hexacyclinic acid monohydrate (HCM), a structurally similar compound (35) (Cambridge Structural Database entry XAFKIY), whose structure is shown in Figure 1. Conversion of the HCM structure to that of cyclostreptin required a few changes. First, the acetyl group at C-8 in HCM was replaced with a hydroxyl group. Next, configuration was changed from $S$ to $R$ at C-9 and $\mathrm{C}-12$. Finally, an olefinic bond ( $E$ configuration) was introduced between $\mathrm{C}-2$ and $\mathrm{C}-17$ by removal of a hydrogen atom at $\mathrm{C}-2$ and a hydroxyl group at $\mathrm{C}-17$ present in $\mathrm{HCM}$.
The modified crystal structure was optimized with the PM3 semiempirical Hamiltonian using MNDO94. The resulting PM3 model of cyclostreptin was found to converge closely to the crystal structure geometry of HCM (root-mean-square deviation $=0.082 \AA$ for all heavy atoms). Molecular mechanics potentials from the CFF91 force field (36) were selected to produce an optimized geometry (norm of final gradient, $1.0 \times 10^{-3} \mathrm{kcal} / \mathrm{mol}$ ) as close as possible to the crystal structure of HCM and the PM3 model of cyclostreptin. The root-mean-square deviation of the CFF91-derived model from the crystal structure was $0.12 \AA$.

The cyclostreptin scaffold is a relatively rigid, multiple, largely aliphatic, fused ring system that possesses only five potential H-bond donors and acceptors. Our next objective was to sample a sufficient amount of conformational space to investigate the combined ring puckering effect on the overlap and steric placement of key molecular substituents that would permit the binding of cyclostreptin in the taxoid site on tubulin polymer. High-temperature molecular dynamics was used to conformationally sample cyclostreptin (cf. ref.19).

A pilot study showed that $1000 \mathrm{~K}$ did not cause inversions of the chiral centers of cyclostreptin using the CFF91 potentials described above. Therefore, this temperature was used for the conformational sampling phase of the molecular modeling. For all molecular dynamics and minimization calculations, the entire functional form of the CFF91 potential energy expression was enabled. Each molecular dynamics simulation started with the minimized crystal structure of cyclostreptin and a new random number seed. The temperature was increased slowly, from $0 \mathrm{~K}$ in $25 \mathrm{~K} / \mathrm{ps}$ increments, until the $1000 \mathrm{~K}$ simulation temperature was reached. All simulations used a time step of $0.5 \mathrm{fs}$ and were initiated with an equilibration phase using direct velocity scaling for $10 \mathrm{ps}$. This phase was followed by $100 \mathrm{ps}$ of molecular dynamics, using the Berendsen method of temperature bath coupling. During this phase of dynamics, a sample structure was collected every $100 \mathrm{fs}$ and minimized with conjugate gradients until the norm of the gradient was $1.0 \times 10^{-3} \mathrm{kcal} / \mathrm{mol}$.

Identification of a Common Pharmacophore between Taxoids and Cyclostreptin and Docking of Cyclostreptin into the Taxoid Site on Tubulin Polymer, As Determined by Molecular Modeling. The optimized cyclostreptin molecular dynamics trajectory was searched for a consistent steric overlap and chemical complementarity with the conformation of docetaxel bound to tubulin. An energy-refined structure (19) of the deposited tubulin structure (21) (PDB entry 1TUB) was used as a starting model for the formation of the cyclostreptin-tubulin molecular model. On the basis of the pharmacophore analysis, the conformational isomer of cyclostreptin that matched docetaxel was docked into the taxoid site until van der Waals contacts of less than $0.25 \AA$ were eliminated. The best pharmacophore-based docking conformation of cyclostreptin had the following features: (1) minimized solvent accessibility when docked into the taxoid site, (2) maximized favorable van der Waals contacts between aliphatic, hydrophobic portions of cyclostreptin and hydrophobic portions, usually amino acid side chains, of the taxoid site, and (3) capability of forming H-bonds either directly or via a water bridge to the taxoid site. Next, the cyclostreptin-tubulin complex was optimized by applying a force of $2000 \mathrm{kcal} \mathrm{mol}^{-1} \AA^{-2}$, and this force was stepped off the 
Table 1: Comparison of the Inhibitory Effects of Cyclostreptin, Paclitaxel, Epothilone A, and Sarcodictyins A and B on the Growth of Human Cancer Cells

\begin{tabular}{|c|c|c|c|c|c|}
\hline \multirow[b]{3}{*}{ compound } & \multicolumn{5}{|c|}{$\mathrm{IC}_{50} \pm \mathrm{SD}(\mathrm{nM})^{a}$} \\
\hline & \multirow{2}{*}{$\frac{\text { breast carcinoma }}{\text { MCF-7 }}$} & \multicolumn{4}{|c|}{ ovarian carcinoma $^{b}$} \\
\hline & & 1A9 & 1А9PTX10 & 1A9PTX22 & 1A9A8 \\
\hline cyclostreptin & $11 \pm 0.9$ & $23 \pm 4$ & $130 \pm 20(6)^{c}$ & $53 \pm 10(2)^{c}$ & $120 \pm 8(5)^{c}$ \\
\hline paclitaxel & $1.5 \pm 0.1$ & $1.9 \pm 0.9$ & $62 \pm 8(33)^{c}$ & $65 \pm 5(34)^{c}$ & $25 \pm 4(13)^{c}$ \\
\hline epothilone A & $5^{d}$ & $1.0 \pm 0.2$ & $6.1 \pm 0.2(6)^{c}$ & $4.0 \pm 2.0(4)^{c}$ & $38 \pm 13(38)^{c}$ \\
\hline sarcodictyin A & $300^{d}$ & $300^{d}$ & $200^{d}$ & $300^{d}$ & \\
\hline sarcodictyin B & $400^{d}$ & $300^{d}$ & $300^{d}$ & $300^{d}$ & \\
\hline
\end{tabular}

${ }^{a} \mathrm{IC}_{50}$ values are mean values obtained in at least three independent experiments. ${ }^{b}$ Parental cell line $1 \mathrm{~A} 9$, a clone of line A2780, was used to select the paclitaxel-resistant (PTX10 and PTX22) and epothilone A-resistant (A8) cell lines. Each resistant cell line contains a different mutation in the M40 $\beta$-tubulin gene. In the PTX10 line, Phe-270 is mutated to valine. In the PTX22 line, Ala-364 is mutated to threonine. In the A8 line, Thr-274 is mutated to isoleucine. ${ }^{c}$ The numbers in parentheses are the calculated relative resistance of each mutant cell line, obtained by dividing the $\mathrm{IC}_{50}$ value of the resistant line by the $\mathrm{IC}_{50}$ value of the $1 \mathrm{~A} 9$ line. ${ }^{d}$ From ref 20 , in which an $\mathrm{IC}_{50}$ value of $2 \mathrm{nM}$ was obtained for paclitaxel against MCF-7 cells.

structure in $100 \mathrm{kcal} \mathrm{mol}^{-1} \AA^{-2}$ decrements by minimizing with conjugate gradients until the norm of the gradient was $1.0 \times 10^{-3} \mathrm{kcal} / \mathrm{mol}$. This process was repeated until all applied external force was removed. ${ }^{3}$

\section{RESULTS}

Effects of Cyclostreptin on the Growth and Mitotic Index of Carcinoma Cells and on the Growth of Drug-Resistant Cells. Table 1 summarizes the inhibitory effects of cyclostreptin, paclitaxel, epothilone $\mathrm{A}$, and, for comparison, sarcodictyins $\mathrm{A}$ and $\mathrm{B}$ on the growth of $\mathrm{MCF}-7$ and $1 \mathrm{~A} 9$ cells. Cyclostreptin was 2-23 times less potent than paclitaxel and epothilone A in these lines but 13-16-fold more potent than the sarcodictyins. Since cyclostreptin displayed feeble paclitaxel-like activity with microtubule protein (9), we evaluated its activity against three paclitaxel- and epothilone-resistant cell lines derived from the 1A9 line. These lines all have mutations in the M40 $\beta$-tubulin gene (details in the footnotes of Table 1), and all exhibited some resistance to cyclostreptin as well as to paclitaxel and epothilone A. However, the paclitaxel-resistant lines, PTX10 and PTX22, both more than 30-fold resistant to paclitaxel relative to the parental line, retained greater sensitivity to cyclostreptin (6- and 2-fold relative resistance, respectively). Similarly, the epothilone-resistant line, 38-fold more resistant to epothilone A than the parental line, retained greater sensitivity to cyclostreptin (5-fold relative resistance).

Human adenocarcinoma HT-29 cells treated with cyclostreptin accumulated in the $\mathrm{G}_{2} / \mathrm{M}$ phase of the cell cycle (9), but compounds that interfere with tubulin function specifically arrest cells in mitosis. We therefore determined the mitotic index of MCF-7 cells treated with cyclostreptin. At $110 \mathrm{nM}, 10$ times the $\mathrm{IC}_{50}$ value, cyclostreptin caused $61 \pm$ $10 \%$ (SD) of the cells to arrest in mitosis as compared with only $3.6 \pm 0.8 \%$ for control cells. Cells treated with $15 \mathrm{nM}$ paclitaxel had a mitotic index of $61 \pm 4 \%$. In contrast to these equivalent mitotic indices at high compound concentrations, at the $\mathrm{IC}_{50}$ 's only $8.0 \pm 1 \%$ of cells treated with paclitaxel were arrested in mitosis as compared with $52 \pm$ $6 \%$ of the cells treated with cyclostreptin.

Cyclostreptin Promotes Cellular Microtubule Bundling Similar to That Which Occurs with Paclitaxel. Since there

\footnotetext{
${ }^{3}$ Further details of the modeling studies, including coordinates, can be obtained from R. Gussio (gussio@ncifcrf.gov).
}

are no published data on the effects of cyclostreptin on cellular microtubules, we examined $\mathrm{PtK}_{2}$ cells treated with the compound following determination of its $\mathrm{IC}_{50}(30 \mathrm{nM}$ vs $760 \mathrm{nM}$ for paclitaxel). Cells treated with 10-fold higher concentrations of either compound displayed extensive bundling of intracellular microtubules and were indistinguishable from each other. Figure 2A shows the microtubule network present in untreated cells. After being treated with cyclostreptin (Figure 2B), microtubules in most cells were thickly bundled, and many cells contained multiple bundles of microtubules. Paclitaxel-treated cells (Figure 2C) had a similar appearance. With both compounds, mitotic cells displayed multiple asters rather than bundled microtubules (not shown).

Effects of Cyclostreptin on Tubulin Assembly: Comparison with Paclitaxel and the Sarcodictyins. Cyclostreptin was described as being substantially less potent than paclitaxel as an inducer of microtubule assembly (9). A reaction required a higher concentration of cyclostreptin, and compound-induced assembly began following a lag period that varied inversely with the concentration of the compound.

Figure 3 presents a detailed investigation of the effects of cyclostreptin on tubulin polymerization. We investigated the effects of temperature, GTP, and MAPs on the cyclostreptininduced reaction, in comparison with paclitaxel and sarcodictyins A and B (the latter two agents were very similar in their effects, and only data obtained with sarcodictyin A are shown in Figure 3). The abilities of many taxoidmimetic agents to promote microtubule formation in the cold and in the absence of GTP or MAPs are characteristics of their enhancement of tubulin assembly. The data presented in Figure 3 demonstrate that cyclostreptin is markedly deficient in these characteristics and is less active than sarcodictyins $\mathrm{A}$ and $\mathrm{B}$, compounds that have a significantly reduced affinity for the taxoid site (20).

Figure 3A summarizes experiments with both MAPs and GTP in the reaction mixture, with stepwise increases in temperature to $30{ }^{\circ} \mathrm{C}$, followed by a period at $0{ }^{\circ} \mathrm{C}$ to assess the cold stability of the polymer formed. At $10^{\circ} \mathrm{C}$, reactions occurred with $10 \mu \mathrm{M}$ paclitaxel and $40 \mu \mathrm{M}$ sarcodictyin A, and slight assembly occurred with $10 \mu \mathrm{M}$ sarcodictyin A. At $15{ }^{\circ} \mathrm{C}$, the reaction rate with $10 \mu \mathrm{M}$ sarcodictyin $\mathrm{A}$ accelerated, and a delayed reaction occurred with $40 \mu \mathrm{M}$ cyclostreptin. Only at $20^{\circ} \mathrm{C}$ did assembly occur with $10 \mu \mathrm{M}$ cyclostreptin. In the control reaction mixture, polymerization 

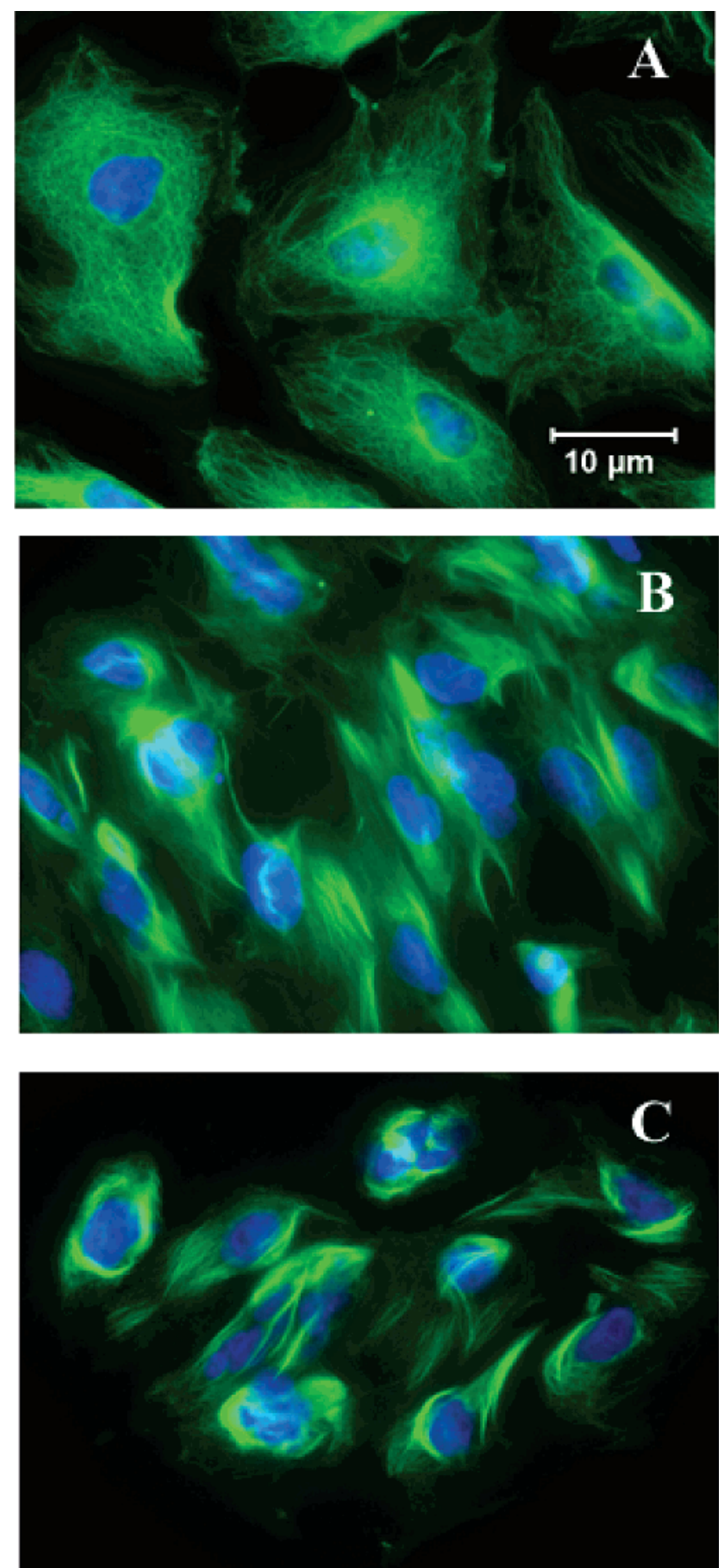

FIGURE 2: Effects of cyclostreptin and paclitaxel on the microtubules of $\mathrm{PtK}_{2}$ cells. Cells were treated with either no compound (A), $300 \mathrm{nM}$ cyclostreptin (B), or $7.6 \mu \mathrm{M}$ paclitaxel (C) for $18 \mathrm{~h}$ prior to fixation and staining. Compound concentrations were 10 fold higher than the $\mathrm{IC}_{50}$ 's. Green represents anti-tubulin antibody and blue DAPI.

initially occurred at $25{ }^{\circ} \mathrm{C}$. When the temperature was returned to $0{ }^{\circ} \mathrm{C}$, control polymer quickly disassembled, as expected. There was a slow loss in turbidity in the reaction mixture containing paclitaxel and a slight loss in turbidity with sarcodictyin A. The reaction mixtures containing cyclostreptin showed no loss of turbidity at $0{ }^{\circ} \mathrm{C}$.

The differences in activity between cyclostreptin and paclitaxel were equally marked when either GTP or MAPs were omitted from the reaction mixture. With GTP only
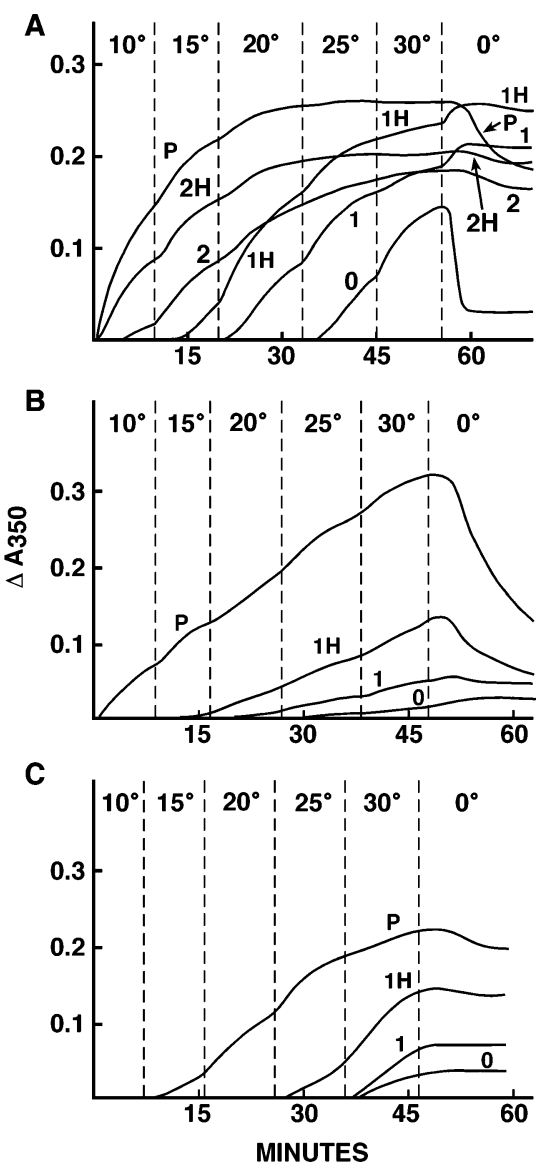

FIGURE 3: Comparison of the effects of cyclostreptin with those of sarcodictyin A and paclitaxel on tubulin assembly with both GTP $(100 \mu \mathrm{M})$ and heat-treated MAPs $(0.75 \mathrm{mg} / \mathrm{mL})(\mathrm{A})$, with GTP only (B), or with heat-treated MAPs only (C). In each panel, compounds are indicated as follows: curve 0 , none; curve 1 , cyclostreptin; curve 2, sarcodictyin A; and curve P, paclitaxel. Compound concentrations were $10 \mu \mathrm{M}$, except that the letter $\mathrm{H}$ indicates that the concentration was $40 \mu \mathrm{M}$. All reaction mixtures contained $10 \mu \mathrm{M}$ tubulin, $0.1 \mathrm{M}$ Mes (pH 6.9), and 4\% DMSO. Reaction mixtures were initially maintained at $0{ }^{\circ} \mathrm{C}$, and the temperature jumps were initiated at the times indicated by the dashed lines to the left of each temperature.

(Figure 3B), $10 \mu \mathrm{M}$ paclitaxel induced assembly at $10^{\circ} \mathrm{C}$, with a further increase in turbidity at each temperature step, while $10 \mu \mathrm{M}$ cyclostreptin caused only a feeble reaction. With $40 \mu \mathrm{M}$ cyclostreptin, a somewhat more vigorous assembly reaction occurred. Both the paclitaxel- and cyclostreptin-induced polymers appeared to disassemble slowly at $0{ }^{\circ} \mathrm{C}$. With MAPs only (Figure 3C), $10 \mu \mathrm{M}$ cyclostreptin was nearly inert, and $40 \mu \mathrm{M}$ cyclostreptin was slightly active at $25{ }^{\circ} \mathrm{C}$. Under these same conditions, $10 \mu \mathrm{M}$ paclitaxel induced weak assembly at $15^{\circ} \mathrm{C}$, with stepwise increases in turbidity at the higher temperatures. In reaction mixtures containing $20 \mu \mathrm{M}$ tubulin alone (no MAPs or GTP), cyclostreptin $(20 \mu \mathrm{M})$ was unable to promote microtubule formation, even at $37^{\circ} \mathrm{C}$, while $20 \mu \mathrm{M}$ paclitaxel did induce assembly at temperatures above $20{ }^{\circ} \mathrm{C}$ (data not shown).

Morphological Evaluation and Length Comparison of Polymer Formed with Cyclostreptin or Paclitaxel. There is no published documentation that it was formation of microtubules that caused the increase in turbidity induced by cyclostreptin, even though many compounds that interact with tubulin can cause the formation of aberrant polymers such as spirals or rings. We therefore examined the cyclos- 

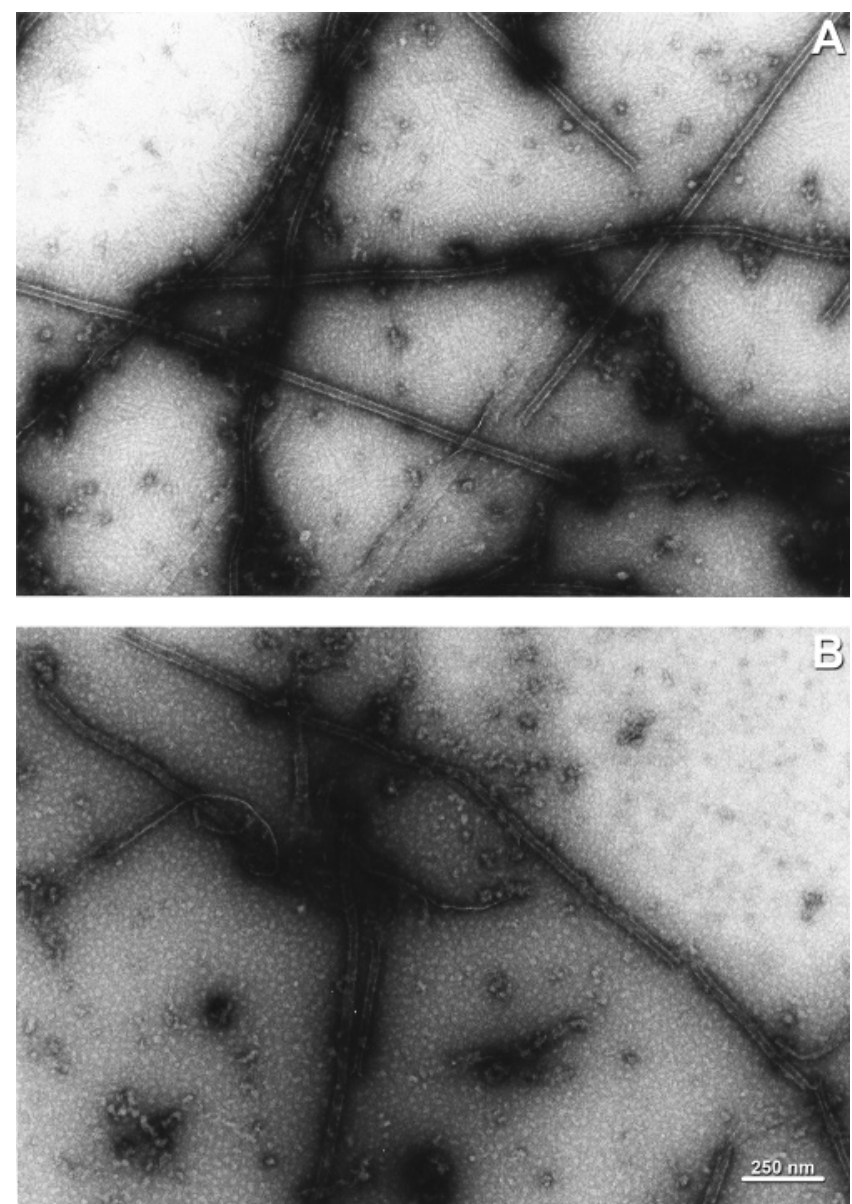

FIGURE 4: Electron micrographs of tubulin polymer formed with $10 \mu \mathrm{M}$ cyclostreptin (A) or $10 \mu \mathrm{M}$ paclitaxel (B). Final reaction mixtures contained $0.1 \mathrm{M}$ Mes (pH 6.9), $10 \mu \mathrm{M}$ tubulin, $0.75 \mathrm{mg} /$ mL heat-treated MAPs, $100 \mu \mathrm{M}$ GTP, 4\% DMSO, and $10 \mu \mathrm{M}$ compound, as indicated. Samples were taken after $30 \mathrm{~min}$ at $30^{\circ} \mathrm{C}$ and an additional $30 \mathrm{~min}$ at $0{ }^{\circ} \mathrm{C}$.

treptin-induced polymer formed in the presence of MAPs and GTP and compared it with the paclitaxel-induced polymer at both $30^{\circ} \mathrm{C}$ and following a return of the reaction mixture to $0{ }^{\circ} \mathrm{C}$. With both compounds and at both temperatures, electron microscopic evaluation of negatively stained specimens showed a polymer mixture consisting of microtubules with some sheet polymers, with only slight differences observed between the two compounds. Typical micrographs of polymer observed at $0{ }^{\circ} \mathrm{C}$ are shown in Figure 4 (panel A, cyclostreptin; panel B, paclitaxel). The most noticeable difference was that microtubules formed with cyclostreptin were longer than those formed with paclitaxel. With paclitaxel, microtubules often contained regions where individual protofilaments appeared to peel away from a microtubule. In samples without the compound (not shown), abundant microtubules without the aberrant polymer were observed at $30^{\circ} \mathrm{C}$, and there was no polymer in $0{ }^{\circ} \mathrm{C}$ samples.

Microtubule lengths were measured on micrographs prepared from $30{ }^{\circ} \mathrm{C}$ reaction mixtures containing both GTP and MAPs. Cyclostreptin formed polymers that were on average twice as long [2.3 $\pm 1.0(\mathrm{SD}) \mu \mathrm{m} ; n=300]$ as those formed with paclitaxel $(1.1 \pm 0.4 \mu \mathrm{m} ; n=235)$, suggesting that cyclostreptin was less able to nucleate tubulin assembly than paclitaxel. Microtubules in the reaction mixture without
Table 2: Comparison of Cyclostreptin with Other Inducers of Microtubule Assembly as Inhibitors of the Binding of $\left[{ }^{3} \mathrm{H}\right]$ Paclitaxel to Tubulin Polymer ${ }^{a}$

\begin{tabular}{lclc}
\hline inhibitor added & $\%$ inhibition \pm SD & inhibitor added & $\%$ inhibition \pm SD \\
\hline cyclostreptin & $55 \pm 5$ & discodermolide & $66 \pm 3$ \\
docetaxel & $51 \pm 3$ & sarcodictyin A & $31 \pm 3$ \\
epothilone A & $47 \pm 4$ & sarcodictyin B & $30 \pm 8$ \\
\hline
\end{tabular}

${ }^{a}$ See the text for the detailed methodology. Tubulin polymer was formed by incubating $2.5 \mu \mathrm{M}$ tubulin with $25 \mu \mathrm{M}$ ddGTP in $0.75 \mathrm{M}$ monosodium glutamate $(\mathrm{pH} 6.6$ with $\mathrm{HCl})$ for $30 \mathrm{~min}$ at $37^{\circ} \mathrm{C}$. The final reaction mixtures contained polymer $(2.0 \mu \mathrm{M}$ tubulin), $2.0 \mu \mathrm{M}$ $\left[{ }^{3} \mathrm{H}\right]$ paclitaxel, and $4.0 \mu \mathrm{M}$ inhibitor, with the polymer added to mixtures containing paclitaxel and inhibitor. Incubation continued for an additional $30 \mathrm{~min}$ at $37^{\circ} \mathrm{C}$. Data represent three to eight repetitions with each compound tested. In these experiments, $15-25 \%$ of the added radiolabeled paclitaxel was recovered in the supernatants in the absence of inhibitor.

compound averaged $3.1 \pm 1.5 \mu \mathrm{m}(n=231)$ in these experiments.

Cyclostreptin Is a Competitive Inhibitor of the Binding of Radiolabeled Paclitaxel to Tubulin Polymer. Since sarcodictyins A and B are weak inhibitors of binding of paclitaxel to tubulin polymer, consistent with their reduced potency as cytotoxins and as enhancers of tubulin polymerization (20; Figure 3A), we anticipated that cyclostreptin would also bind relatively weakly to tubulin polymer. The radiolabeled paclitaxel assay we use involves adding preformed microtubules at $37{ }^{\circ} \mathrm{C}$ to a mixture of $\left[{ }^{3} \mathrm{H}\right]$ paclitaxel and potential inhibitor. In this assay, more than $90 \%$ of the tubulin in the initial reaction mixture is driven into polymer by use of glutamate and ddGTP (20).

Contrary to expectations, cyclostreptin strongly inhibited binding of paclitaxel to polymer and was exceeded in potency only by discodermolide (Table 2). Even though cyclostreptin is less effective than the sarcodictyins as an inducer of tubulin assembly (Figure 3A), it more potently inhibited the binding of $\left[{ }^{3} \mathrm{H}\right]$ paclitaxel to polymer.

More detailed studies were performed and examined by Hanes analysis (29), in which the substrate concentration is plotted against substrate concentration divided by the amount of substrate bound, and results consistent with cyclostreptin acting as a competitive inhibitor of paclitaxel binding were obtained. The original Hanes analysis was derived for enzymatic reactions with substrate and inhibitor in large excess over enzyme (29), leading us to derive a modified Hanes analysis for equilibrium data. The only limitation to the method is that, with only paclitaxel being radiolabeled and measurable, it requires estimation of the unbound cyclostreptin concentrations. Using these estimates, a family of near-parallel lines at different cyclostreptin concentrations was obtained (Figure 5), confirming that the compound acts as a competitive inhibitor of paclitaxel binding. Moreover, the abscissa intercept of the curve representing reaction mixtures without cyclostreptin (circles) yielded an apparent $K_{\mathrm{d}}$ value of $96 \pm 20$ (SE) $\mathrm{nM}$ for paclitaxel. This value is identical to the value of $93 \mathrm{nM}$ obtained at $37{ }^{\circ} \mathrm{C}$ when inhibition by paclitaxel of binding of Flutax-2 to glutaraldehyde-fixed microtubules was examined (34).

The abscissa intercepts of the curves representing reaction mixtures containing cyclostreptin permitted calculation of an apparent $K_{\mathrm{i}}$ value for cyclostreptin. The three curves yielded values of 99,81 , and $88 \mathrm{nM}$, or an average of $89 \pm$ 5 (SE) nM. This value is 16 -fold lower than that obtained 


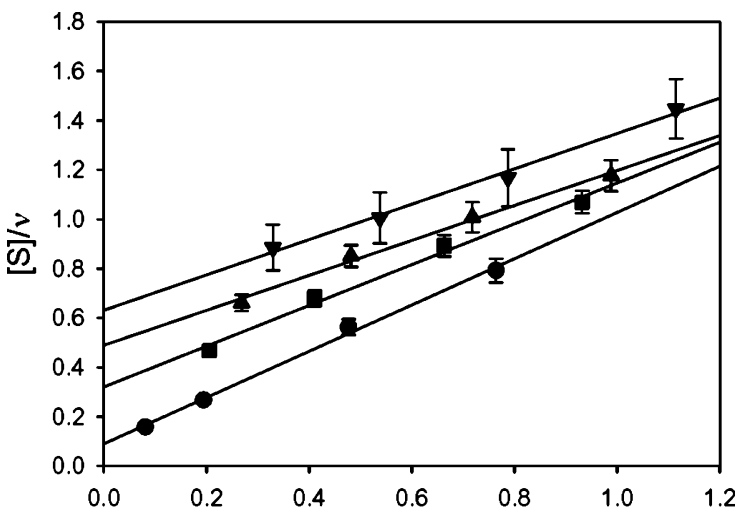

[S]

FIGURE 5: Inhibition of the binding of $\left[{ }^{3} \mathrm{H}\right]$ paclitaxel to tubulin polymer by cyclostreptin shows a competitive pattern. Varying concentrations of $\left[{ }^{3} \mathrm{H}\right]$ paclitaxel $(1.0,1.5,2.0$, or $2.5 \mu \mathrm{M})$ and of cyclostreptin $(0,0.5,0.75$, or $1.0 \mu \mathrm{M})$ were added to preformed microtubule polymer and incubated for $30 \mathrm{~min}$ at $37^{\circ} \mathrm{C}$. The free paclitaxel concentrations were calculated from the data, and the free cyclostreptin concentrations were estimated as described. The data are presented in the modified Hanes format, as derived in the text, with the lines drawn by linear regression: $(\mathbf{0})$ no cyclostreptin,

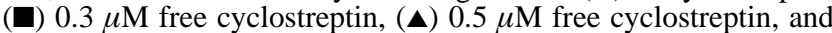
(v) $0.7 \mu \mathrm{M}$ free cyclostreptin. Abscissa units are micromolar free paclitaxel. Ordinate units are micromolar free paclitaxel divided by fractional saturation of binding sites by paclitaxel. SEs are shown, unless they are smaller than the size of the symbols.

when total paclitaxel and cyclostreptin concentrations were used in the analysis (data not presented). A similar difference would probably be found if data previously used to determine $K_{\mathrm{i}}$ values for other taxoid site compounds were re-evaluated using free instead of total compound concentrations.

Inhibition of Binding of Flutax-2 to Microtubules Demonstrates the Interaction of Cyclostreptin with the Taxoid Binding Site on Microtubules Is Entropy-Driven and Endothermic. We wished to gain insight into the decreased activity of cyclostreptin as an inducer of tubulin polymerization at low temperatures, but the polymer used in the $\left[{ }^{3} \mathrm{H}\right]$ paclitaxel binding studies was too labile. Therefore, we evaluated the inhibitory effect of cyclostreptin on the binding of Flutax-2 to glutaraldehyde-fixed microtubules at various temperatures.

As in the $\left[{ }^{3} \mathrm{H}\right]$ paclitaxel system, at $35{ }^{\circ} \mathrm{C}$ cyclostreptin bound efficiently to the taxoid site in pre-existing polymer in competition with Flutax-2. Assuming 1:1 stoichiometry, the apparent $K_{\mathrm{a}}$ value determined at $35^{\circ} \mathrm{C}$ for cyclostreptin was $2.06 \times 10^{7} \mathrm{M}^{-1}$, intermediate between the values obtained for paclitaxel $\left(1.43 \times 10^{7} \mathrm{M}^{-1}\right)$ and docetaxel (3.93 $\times 10^{7} \mathrm{M}^{-1}$ ) (Figure 6A and Table 3). When inhibition of Flutax-2 binding was examined at $4{ }^{\circ} \mathrm{C}$, the binding constants of paclitaxel and docetaxel were not very different from the $35{ }^{\circ} \mathrm{C}$ values: the apparent $K_{\mathrm{a}}$ values for paclitaxel and docetaxel were $0.86 \times 10^{7}$ and $2.36 \times 10^{7} \mathrm{M}^{-1}$, respectively (Figure 6B and Table 3). In contrast, the binding constant obtained for cyclostreptin at $4{ }^{\circ} \mathrm{C}, 3.27 \times 10^{5} \mathrm{M}^{-1}$, was more than 60 -fold lower than the $35^{\circ} \mathrm{C}$ value.

This difference between the compounds led us to examine the inhibitory effects of cyclostreptin on binding of Flutax-2 to microtubules across the temperature range from 26 to 42 ${ }^{\circ} \mathrm{C}$. Comparative studies were performed simultaneously with paclitaxel and docetaxel (34). As reported previously with the taxoids (34), there was a progressive decrease in the $K_{\mathrm{a}}$ values in this temperature range: with paclitaxel, from 2.64 to $0.94 \times 10^{7} \mathrm{M}^{-1}$; and with docetaxel, from 6.95 to $2.38 \times$

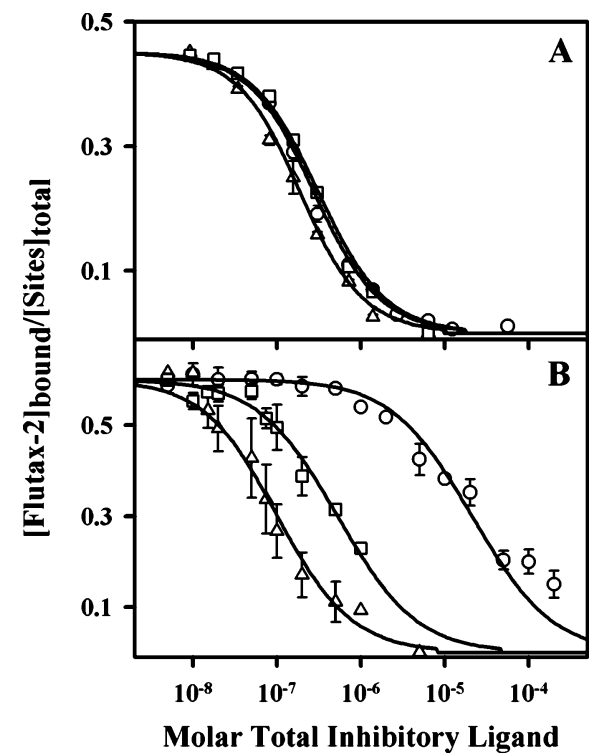

FIGURE 6: Inhibition of binding of Flutax-2 $(50 \mathrm{nM})$ to microtubule binding sites $(50 \mathrm{nM})$ at $35(\mathrm{~A})$ and $4{ }^{\circ} \mathrm{C}(\mathrm{B})$. The curves were generated for the best-fit value of the binding equilibrium constant of each competitor, assuming a 1:1 binding to the same site as Flutax-2: $(O)$ cyclostreptin, $(\square)$ paclitaxel, and $(\triangle)$ docetaxel. SEs are shown, unless they are smaller than the size of the symbols.

$10^{7} \mathrm{M}^{-1}$. Conversely, there was a progressive increase in the $K_{\mathrm{a}}$ value for cyclostreptin as the temperature rose (from 1.02 to $2.84 \times 10^{7} \mathrm{M}^{-1}$ ). When these data were examined in the van't Hoff format (Figure 7), the difference between cyclostreptin and the taxoids was striking. In contrast to the relatively greater enthalpic, exothermic profile of binding of paclitaxel and docetaxel to microtubules, the binding of cyclostreptin was characterized by a more entropic, endothermic profile (see Table 3). We attribute the enhanced entropic effect that occurs with cyclostreptin to its large hydrophobic volume, which, when the compound is unbound, is solvent exposed. Cyclostreptin has few substituents that favor water solubility (the hydroxyls at C- 6 and C- 8 and the carbonyl oxygen atom at C-1), and the C-6 hydroxyl and the carbonyl oxygen atom are involved in intramolecular $\mathrm{H}$ bonding and can contribute little to enhance the compound's water solubility. With paclitaxel and docetaxel, the mostly aliphatic baccatin ring system and the phenyl and aliphatic groups of the side chains have a greater number of H-bond donors and acceptors that are spatially distinct and almost uniformly spread throughout the taxoid molecules and are involved in their binding interactions with tubulin $(19,21)$.

Is Cyclostreptin, Relative to Paclitaxel, More Deficient in Promoting Nucleation or Elongation? The mechanism by which taxoidmimetic compounds induce tubulin assembly at low temperatures and in the absence of MAPs and/or GTP is not clear, since the affinity of these compounds for tubulin polymers is much higher than for $\alpha \beta$-heterodimers (37-39). Do these compounds participate in nucleation reactions, or do they only enhance the elongation phase of assembly? The shorter average microtubule lengths observed with this class of compounds, together with increased net polymer assembly, suggest that both nucleation and elongation reactions are enhanced. Moreover, with a number of compounds [discodermolide $(4,40)$, epothilone B $(41)$, and 2-debenzoyl-2-metaazidobenzoylpaclitaxel (42)], enhanced assembly relative to that of paclitaxel at low temperatures and without MAPs and 
Table 3: Apparent Thermodynamic Parameters of Binding of Cyclostreptin, Paclitaxel, and Docetaxel to the Taxoid Binding Site of Microtubules $^{a}$

\begin{tabular}{lcccccc}
\hline \multicolumn{1}{c}{ ligand } & $\begin{array}{c}K_{\text {app }}\left(35^{\circ} \mathrm{C}\right)^{b} \\
\left(\times 10^{5} \mathrm{M}^{-1}\right)\end{array}$ & $\begin{array}{c}K_{\text {app }}\left(4^{\circ} \mathrm{C}\right)^{c} \\
\left(\times 10^{5} \mathrm{M}^{-1}\right)\end{array}$ & $\begin{array}{c}\Delta H_{\text {app }}{ }^{\circ} \\
(\mathrm{kJ} / \mathrm{mol})\end{array}$ & $\begin{array}{c}\Delta S_{\text {app }}{ }^{d} \\
\left(\mathrm{~J} \mathrm{~mol}^{-1} \mathrm{~K}^{-1}\right)\end{array}$ & $\begin{array}{c}\Delta G^{\circ}{ }_{\text {app }}\left(4^{\circ} \mathrm{C}\right)^{c} \\
(\mathrm{~kJ} / \mathrm{mol})\end{array}$ & $\begin{array}{c}\Delta G^{\circ}{ }_{\text {app }}\left(35^{\circ} \mathrm{C}\right)^{e} \\
(\mathrm{~kJ} / \mathrm{mol})\end{array}$ \\
\hline cyclostreptin & $206 \pm 11$ & $3.27 \pm 0.90$ & $43 \pm 7$ & $278 \pm 19$ & $-29.2 \pm 0.6$ & $-43.1 \pm 0.1$ \\
paclitaxel & $143 \pm 17$ & $86 \pm 32$ & $-51 \pm 4$ & $-28 \pm 13$ & $-36.7 \pm 0.7$ & $-42.2 \pm 0.2$ \\
docetaxel & $393 \pm 27$ & $236 \pm 87$ & $-52 \pm 2$ & $-25 \pm 8$ & $-39.1 \pm 0.7$ & $-44.8 \pm 0.2$ \\
\hline
\end{tabular}

${ }^{a}$ All numerical values are shown \pm SE. $K_{\text {app }}$ values as a function of temperature were used to derive the thermodynamic parameters with the Gibbs and van't Hoff equations. ${ }^{b} K_{\text {app }}$ values at $35^{\circ} \mathrm{C}$ calculated from the data shown in Figure $6 \mathrm{~A}$ for cyclostreptin. The values for paclitaxel and docetaxel obtained from the experiments depicted in Figure 6A were within the experimental errors described in ref 34 , and the results from these more extensive observations are reiterated here. ${ }^{c}$ Derived from analysis of the experiments summarized in Figure $6 \mathrm{~B} .{ }^{d}$ Values calculated for the interval $26-42{ }^{\circ} \mathrm{C} .{ }^{e}$ Derived from analysis of the experiments summarized in Figure 6A for cyclostreptin. The values for paclitaxel and docetaxel obtained from the data summarized in Figure 6A fall within the experimental range observed in ref 34, and the results from these more extensive observations are reiterated here.

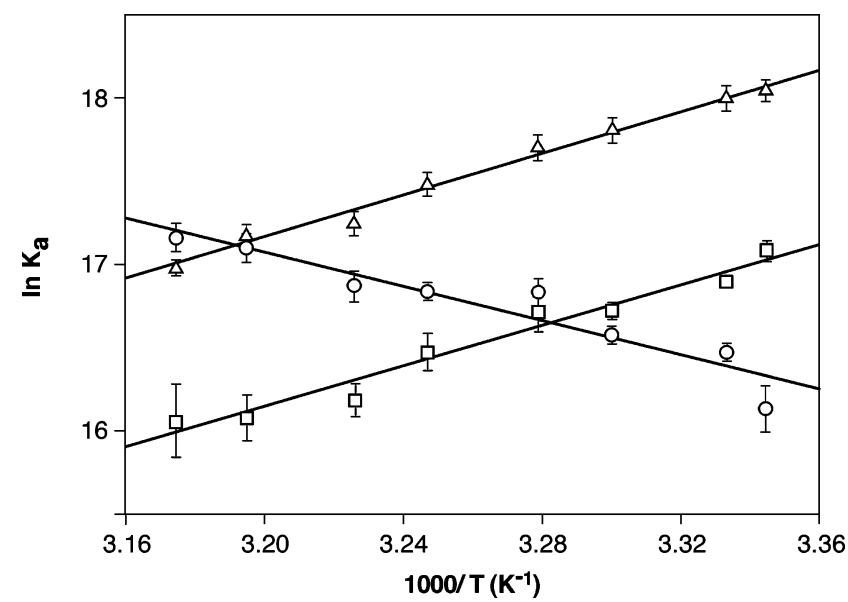

FIGURE 7: van't Hoff representation of the dependence of paclitaxel, docetaxel, and cyclostreptin equilibrium binding constants on temperature (best regression lines calculated from the data in the interval from 26 to $\left.42{ }^{\circ} \mathrm{C}\right)$ : $(\bigcirc)$ cyclostreptin, $(\square)$ paclitaxel, and $(\triangle)$ docetaxel. SEs are shown, unless they are smaller than the size of the symbol.

GTP occurs in tandem with formation of very short microtubules, relative to what is observed with paclitaxel. This suggests that these properties are markers for "hypernucleation", by which we mean a compound-induced increase in the number of nuclei at any tubulin concentration relative to the number of nuclei formed in the absence of the compound.

The weakened ability of cyclostreptin relative to paclitaxel to promote assembly at low temperatures and without MAPs and GTP suggests that this compound may be relatively deficient in enhancing nucleation. This is supported by the finding that the average microtubule length relative to the control without compound was reduced by $\sim 25 \%$ with cyclostreptin as opposed to $65 \%$ with paclitaxel. The similar affinities of cyclostreptin and paclitaxel for microtubules at $30-32{ }^{\circ} \mathrm{C}$ (Figure 7) suggested an additional approach to gaining insight into relative compound effects on nucleation and elongation.

In the experiments summarized in Table 4, with illustrative examples shown in Figure 8, reaction mixtures without GTP or compound were rapidly warmed to $30^{\circ} \mathrm{C}$, with compound or DMSO and GTP subsequently added and rapidly mixed into the samples $(15-20 \mathrm{~s})$. Turbidity development was followed, with the maximum elongation rate determined from the tangent to the inflection point of the sigmoidal turbidity curve and the lag period from the intercept of this tangent with the baseline. In addition, the amount of protein
Table 4: Parameters of Tubulin Assembly when GTP,

Cyclostreptin, and/or Paclitaxel Were Added to Reaction Mixtures Prewarmed to $30^{\circ} \mathrm{C}$

\begin{tabular}{|c|c|c|c|}
\hline additions at $30^{\circ} \mathrm{C}$ & $\begin{array}{l}\text { lag time } \\
\pm \mathrm{SD}^{a}(\mathrm{~s})\end{array}$ & $\begin{array}{c}\text { elongation } \\
\text { rate } \pm \mathrm{SD}^{a}\left(A_{350}\right. \\
\text { milliunits } / \mathrm{min})\end{array}$ & $\begin{array}{l}\text { extent of } \\
\text { assembly } \pm \mathrm{SD}^{b} \\
\text { (\% protein } \\
\text { in pellet })\end{array}$ \\
\hline GTP & $54 \pm 6$ & $37 \pm 7$ & $30 \pm 2$ \\
\hline $\begin{array}{l}10 \mu \mathrm{M} \text { cyclostreptin } \\
\text { with GTP }\end{array}$ & $47 \pm 10$ & $42 \pm 10$ & $35 \pm 4$ \\
\hline $\begin{array}{l}40 \mu \mathrm{M} \text { cyclostreptin } \\
\text { with GTP }\end{array}$ & $35 \pm 4$ & $69 \pm 6$ & $44 \pm 3$ \\
\hline $\begin{array}{l}10 \mu \mathrm{M} \text { paclitaxel } \\
\text { with GTP }\end{array}$ & $3 \pm 2$ & $260 \pm 50$ & $59 \pm 3$ \\
\hline
\end{tabular}

${ }^{a}$ Reaction mixtures contained (in a final volume of $0.25 \mathrm{~mL}$ ) 1.0 $\mathrm{mg} / \mathrm{mL}$ tubulin, $0.75 \mathrm{mg} / \mathrm{mL}$ heat-treated MAPs, $0.1 \mathrm{M}$ Mes ( $\mathrm{pH}$ 6.9), and 3\% DMSO in $0.245 \mathrm{~mL}$. Samples were run individually, and each was placed in a cuvette held at $0{ }^{\circ} \mathrm{C}$. The baseline was established, and the temperature was jumped to $30^{\circ} \mathrm{C}$. Approximately 3 min later, $5 \mu \mathrm{L}$ of either $50 \%$ DMSO, $5 \mathrm{mM}$ GTP in $50 \%$ DMSO, or $5 \mathrm{mM}$ GTP with $0.5 \mathrm{mM}$ paclitaxel, $0.5 \mathrm{mM}$ cyclostreptin, or $2.0 \mathrm{mM}$ cyclostreptin in 50\% DMSO was added to the bottom of the cuvette and rapidly mixed into the reaction mixture with a Pasteur pipet. The period when the cuvette chamber was open produced a gap in the tracing, and the midpoint in each gap was taken to be time zero for the purpose of determining the lag time. Tangents were drawn to the inflection points of the sigmoidal turbidity tracings to determine the maximum elongation rate and the lag period (intercept of the tangent with the baseline). Reaction mixtures without GTP showed no significant change in turbidity (see Figure 8, curve B), and no correction was made to the data for this background reaction. Each reaction condition was examined seven or eight times. ${ }^{b}$ Reaction mixtures were prepared as described above, except that their volume was $0.10 \mathrm{~mL}$. GTP and GTP/compound mixtures were added after the reaction mixtures had been warmed to $30{ }^{\circ} \mathrm{C}$ for $\sim 3 \mathrm{~min}$. They were then incubated for $10 \mathrm{~min}$ at $30^{\circ} \mathrm{C}$ and centrifuged at $30^{\circ} \mathrm{C}$ for $10 \mathrm{~min}$ at $30000 \mathrm{rpm}$ in a Beckman TLA100 rotor in an Optima TLX centrifuge. The amount of protein in the supernatants was determined (Lowry assay) as a percentage of the total protein, and the difference was taken as the percentage of protein in the pellet. Without an incubation and without GTP, an average of $5.7 \%$ of the protein was in the pellet, and the values for the other samples were corrected by this amount. Each reaction condition was examined three times.

incorporated into polymer was determined by centrifugation, in separate experiments. (The pellet size after $60 \mathrm{~min}$ did not differ significantly from that formed after $10 \mathrm{~min}$ for any reaction condition.)

When added with GTP at $30{ }^{\circ} \mathrm{C}$, cyclostreptin at $10 \mu \mathrm{M}$ had little effect on any parameter of the tubulin assembly reaction, as compared with GTP alone, except for the cold stability of the polymer. Increasing the cyclostreptin concentration to $40 \mu \mathrm{M}$ resulted in a shorter lag phase, an increased elongation rate, a higher final turbidity reading, 


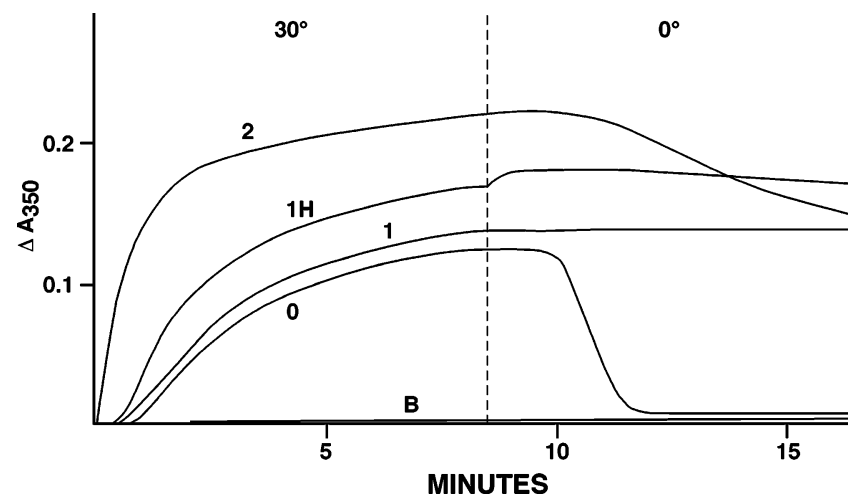

FIGURE 8: Effects of cyclostreptin and paclitaxel when added with GTP to reaction mixtures prewarmed to $30{ }^{\circ} \mathrm{C}$. See the footnotes of Table 4 for experimental details. At the time indicated by the vertical dashed line, the temperature controller was set at $0{ }^{\circ} \mathrm{C}$, but it takes $\sim 4-5 \mathrm{~min}$ for cuvette contents to reach that temperature: curve B, no GTP or compound; curve $0,100 \mu \mathrm{M}$ GTP only; curve $1,10 \mu \mathrm{M}$ cyclostreptin and $100 \mu \mathrm{M}$ GTP; curve $1 \mathrm{H}, 40 \mu \mathrm{M}$ cyclostreptin and $100 \mu \mathrm{M}$ GTP; and curve $2,10 \mu \mathrm{M}$ paclitaxel and $100 \mu \mathrm{M}$ GTP.

and a larger pellet, although in no case were these values comparable with those obtained with $10 \mu \mathrm{M}$ paclitaxel.

With $10 \mu \mathrm{M}$ paclitaxel, the lag phase was very brief and difficult to measure precisely. The lag was at least 18 times shorter than with GTP only, 16 times shorter than with 10 $\mu \mathrm{M}$ cyclostreptin, and 12 times shorter than with $40 \mu \mathrm{M}$ cyclostreptin. The maximum elongation rate, in terms of turbidity development, was also substantially greater with paclitaxel, 6-7-fold faster than with GTP only or with 10 $\mu \mathrm{M}$ cyclostreptin and GTP and almost 4-fold faster than with $40 \mu \mathrm{M}$ cyclostreptin and GTP. Finally, the extent of the reaction was increased more with $10 \mu \mathrm{M}$ paclitaxel than with either concentration of cyclostreptin.

The elongation rates shown in Table 4 , however, do not take into account the different numbers of microtubules present in each reaction mixture. Combining average microtubule lengths with assembly extent data, we can estimate that there were 1.6-fold more microtubules formed with 10 $\mu \mathrm{M}$ cyclostreptin and GTP and 5.5-fold more formed with $10 \mu \mathrm{M}$ paclitaxel and GTP than with GTP only. If the elongation rates are corrected for these relative numbers of microtubules, the $10 \mu \mathrm{M}$ cyclostreptin rate becomes 26 instead of 42 milliunits of $A_{350} / \mathrm{min}$ and the $10 \mu \mathrm{M}$ paclitaxel rate becomes 47 instead of 260 milliunits/min as compared with the rate of 37 milliunits/min without either compound. The primary effect of both compounds appears to be at the nucleation level, since the apparent elongation rate per microtubule is similar under the three reaction conditions.

Molecular Modeling. When we modeled cyclostreptin into the taxoid site on tubulin polymer $(19,21)$, we found that the cyclostreptin molecule formed a common pharmacophore with taxoids. The crystal structure of HCM (35) has a strong intramolecular $\mathrm{H}$-bond between the $\mathrm{C}$ - 1 carbonyl oxygen atom and the C-6 hydroxyl group, and this bond persists in our cyclostreptin model. The distance between the oxygen atoms is $2.94 \AA$ (Figure 9A). There is a similar intramolecular $\mathrm{H}$-bond in docetaxel between the C-9 carbonyl oxygen atom and the $\mathrm{C}-10$ hydroxyl group (interatomic distance, $2.76 \AA$ ). In this description, we will therefore compare cyclostreptin with docetaxel.

Although the cyclostreptin structure is relatively rigid, introduction of minor puckering into the fused hydrocarbon ring system yielded a number of low-energy conformers that superimposed extensively onto the baccatin III ring structure and the $\mathrm{C}-1^{\prime}$ carbonyl group in the $\mathrm{C}-13$ side chain of docetaxel (Figure 9). We found that the best atom-to-atom correspondence in the space-filling pharmacophore was between most of the oxygen atoms in the two compounds. In Figure 9A, we indicate (" $\mathrm{X}$ " in each structure) the overlapping centroids (average position of the oxygen atoms in Cartesian space) and distances from the centroids to

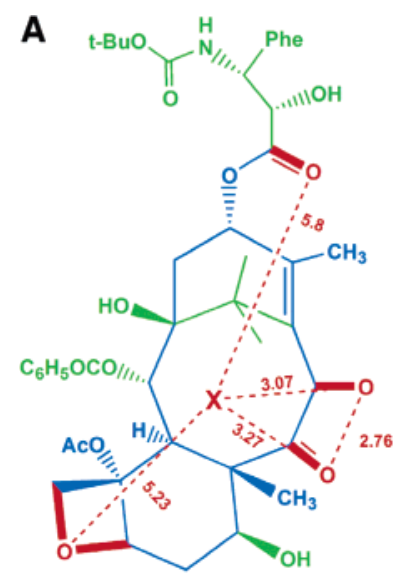

Docetaxel

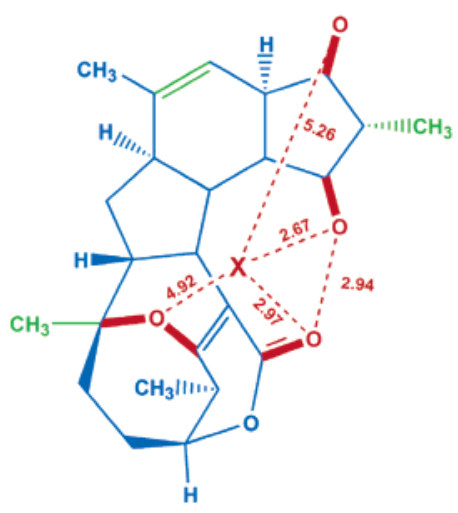

Cyclostreptin

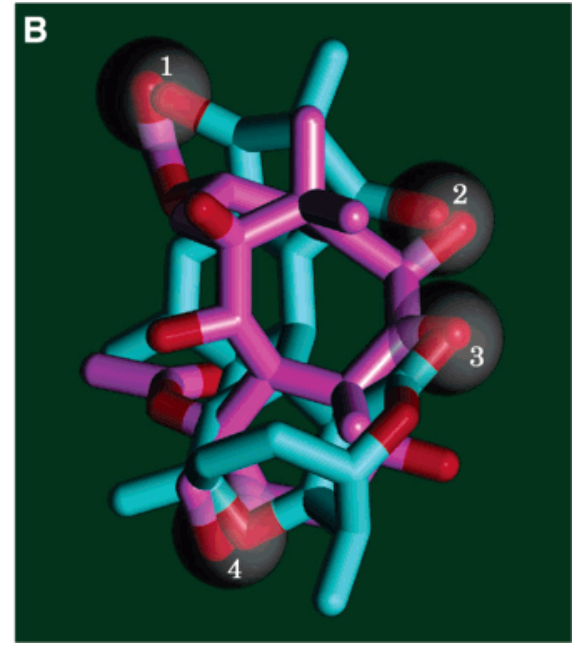

FIGURE 9: Cyclostreptin-docetaxel pharmacophore. (A) The closest atom-to-atom correspondence in the pharmacophore is in the four sets of oxygen atoms shown in red, with their bonds indicated by the bold, red rectangles. Distances from the centroid (indicated by $\mathrm{X}$ ) in angstroms in both compounds are shown, as well as the lengths of the intramolecular H-bonds (see the text) that are included in the pharmacophore. When the two compounds are superimposed, the root-mean-square deviation between corresponding oxygen atoms is 0.49 A. Additional elements of van der Waals overlap in the pharmacophore are colored blue, while nonshared structural elements are colored green. (B) Cyclostreptin (carbons in cyan) overlaps with the docetaxel (carbons in magenta) baccatin III ring system. Transparent gray spheres 1-3 correspond to the three H-bonding centers of the cyclostreptin-docetaxel overlap, and sphere 4 corresponds to the overlapping ether systems. Spheres 1-4 contain the overlap pairs for oxygen atoms at C-8 and C-1', at C-6 and C-10, at C-1 and C-9, and O-16 and the oxetane ring oxygen atom, respectively (positions in cyclostreptin and docetaxel, respectively; see Figure 1). Oxygen atoms in both compounds are colored red. The docetaxel C-13 side chain is not shown beyond $\mathrm{C}-1^{\prime}$ for clarity. 


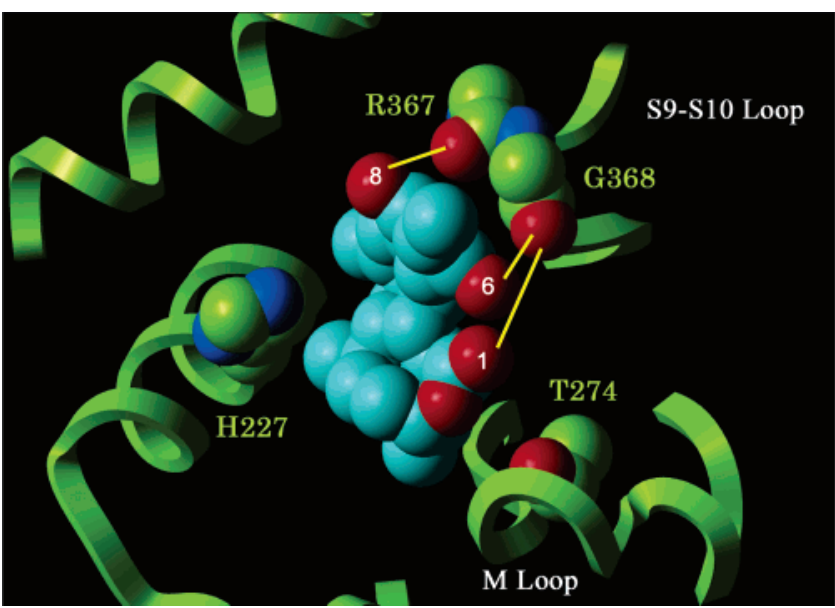

FIGURE 10: Projection (20 A) of cyclostreptin docked into the taxoid site. The space filling model of cyclostreptin (carbon atoms in cyan) is docked into the taxoid binding site of $\beta$-tubulin (green ribbon, with selected side chain carbon atoms in green, oxygen in red, and nitrogen in dark blue), based on a common pharmacophore with taxoids. Cyclostreptin hydroxyl groups at C-8 and C-6 form waterbridged H-bonds (yellow lines) with the backbone carbonyl groups of Arg-367 and Gly-368 (located on the S9-S10 loop), respectively. Docking studies also suggest that the lactone carbonyl oxygen at the $\mathrm{C}-1$ atom of cyclostreptin may also form a bridge via several water molecules to the backbone carbonyl of Gly-368 and to the side chain hydroxyl of Thr-274. For reference, the side chains of Thr-274 (located on the M loop) and His-227 (located on H7) are displayed as space filling models. Helix H1 is shown in the top left-hand corner.

corresponding oxygen atoms. In docetaxel and cyclostreptin, these are (see Figure 1 for details of position numbers) the ether atoms of the oxetane ring oxygen and $\mathrm{O}-16$; the carbonyl oxygen atoms at C-9 and C-1; the hydroxyl oxygen atoms at $\mathrm{C}-10$ and $\mathrm{C}-6$; and the oxygen atoms at $\mathrm{C}-1^{\prime}$ and C-8, respectively. Figure 9A also shows, in blue, segments of each compound encompassed in the common pharmacophore and, in green, unique segments not in the pharmacophore. Figure 9B provides the same details in overlapping three-dimensional models, again with emphasis on the corresponding oxygen atoms. Conformational studies of the structures of the compounds combined with iterative fitting of cyclostreptin onto the structure of docetaxel bound to tubulin polymer consistently showed the overlap shown in Figure 9.

Furthermore, this pharmacophore-based conformation of cyclostreptin displayed good steric complementarity with the taxoid site, following docking into the site (Figure 10), in a manner that maximized favorable contacts with tubulin and minimized solvent exposure of the aliphatic portions of cyclostreptin. The cyclostreptin-protein interaction is characterized by water-bridged $\mathrm{H}$-bonds involving the polypeptide carbonyl groups of Arg-367 (with the C-8 hydroxyl group of cyclostreptin) and Gly-368 (with the C-6 hydroxyl and $\mathrm{C}-1$ carbonyl oxygen atom) of the S9-S10 loop. The bridge between Gly-368 and the C-1 oxygen atom of cyclostreptin involves more water molecules than is the case with the other two H-bonds. The $\mathrm{C}-1$ oxygen atom may also form a water-mediated H-bond with Thr-274 of the M loop. The docked structure of cyclostreptin also fits snugly into a complementary hydrophobic cavity formed by the side chains of $\beta$-tubulin residues Ala-231, Phe-270, and leucines 215, 228, 273, and 369 (not shown).
Cyclostreptin has a significantly lower capacity than taxoids for forming $\mathrm{H}$-bonding interactions with $\beta$-tubulin. The larger hydrocarbon core of cyclostreptin may be sufficient for stabilizing the $\mathrm{M}$ loop through hydrophobic collapse, requiring fewer enthalpic interactions than do the taxoids. This observation agrees with the conclusion derived from the temperature data (Figure 7) that the energetics for binding of cyclostreptin to tubulin polymer are dominated by the their greater entropic profile, in contrast to the relatively greater enthalpic profile in the energetics of taxoid binding.

\section{DISCUSSION}

Previous work had indicated tubulin was the target of cyclostreptin $(8,9)$, although additional targets are possible (43). Compared with paclitaxel, cyclostreptin weakly increased turbidity development with microtubule protein, had significant activity against cells in culture, caused $\mathrm{G}_{2} / \mathrm{M}$ arrest, and was active in two in vivo murine tumor models.

We directly compared cyclostreptin with paclitaxel in several cell lines. The ratio of $\mathrm{IC}_{50}$ values (cyclostreptin: paclitaxel) ranged from 0.04 in the $\mathrm{PtK}_{2}$ line to 12 in the 1A9 line. In MCF-7 cells, both compounds caused an increase in the mitotic index, more marked with cyclostreptin than paclitaxel. In $\mathrm{PtK}_{2}$ cells, dramatic and similar bundling of microtubules occurred with equitoxic concentrations. With the ovarian carcinoma cells, we compared the two compounds in the parental line and in three lines isolated for resistance to paclitaxel or epothilone A. Although the latter lines had reduced sensitivity to cyclostreptin, the loss of sensitivity was not as great as that which occurred with paclitaxel and epothilone A. These observations, the ready supply of cyclostreptin available by fermentation (8) and synthesis $(16,17)$, and its in vivo activity make cyclostreptin a promising candidate for drug development.

Our primary interest here has been to understand the biochemical mechanism underlying the deficiency of cyclostreptin in inducing tubulin assembly, even though the compound is a strong competitive inhibitor of binding of paclitaxel to tubulin polymer. Parameters of the assembly reaction with cyclostreptin suggested a significant deficiency of the compound in hypernucleating assembly relative to paclitaxel. There was a much longer lag in initiation with cyclostreptin than with paclitaxel, or even with sarcodictyins A and B, in assembly dependent on both GTP and MAPs. Microtubules formed with cyclostreptin were twice as long as those formed with paclitaxel. Moreover, cyclostreptin had a limited ability to induce assembly at low temperatures or without GTP and/or MAPs compared with paclitaxel.

To characterize the interaction of cyclostreptin with tubulin, we first examined its inhibition of the binding of $\left[{ }^{3} \mathrm{H}\right]$ paclitaxel to microtubules at $37{ }^{\circ} \mathrm{C}$. Unexpectedly, cyclostreptin proved to be a strong inhibitor, comparable in its effect to docetaxel and epothilone A, both highly active promoters of assembly $(3,44)$. Like data obtained previously with docetaxel and epothilone A (41), the data for cyclostreptin inhibition yielded a competitive pattern. Such a result implies that cyclostreptin and paclitaxel bind at the same site in tubulin polymer. Using a modified analysis, based on free compound concentrations, we found that cyclostreptin was a competitive inhibitor of binding of paclitaxel to tubulin 
polymer and obtained a $K_{\mathrm{d}}$ value for paclitaxel of $96 \mathrm{nM}$ and a $K_{\mathrm{i}}$ value for cyclostreptin of $88 \mathrm{nM}$.

To obtain a more comprehensive understanding of the interaction of cyclostreptin with tubulin polymer and better quantitation of its high affinity for microtubules at $37{ }^{\circ} \mathrm{C}$, we used the Flutax-2 binding assay $(30,31)$. In contrast to the $2 \mu \mathrm{M}$ polymer tubulin used with $\left[{ }^{3} \mathrm{H}\right]$ paclitaxel, only 50 $\mathrm{nM}$ polymer tubulin was needed to examine inhibition of Flutax-2 binding. The initial study at $35^{\circ} \mathrm{C}$ demonstrated that cyclostreptin, docetaxel, and paclitaxel had similar affinities for the taxoid site $\left(K_{\mathrm{d}}\right.$ values of 49,25 , and 70 $\mathrm{nM}$, respectively).

When inhibition of binding of Flutax-2 by cyclostreptin or taxoids was examined at $26-42{ }^{\circ} \mathrm{C}$, a marked difference was observed between the compounds. With the taxoids, there was a slow decline with an increase in temperature in the apparent $K_{\mathrm{a}}$ values derived from the inhibitory data. In the van't Hoff format, the $K_{\mathrm{a}}$ values led to the conclusion that taxoid binding is characterized by a greater exothermic, enthalpic profile (34). With cyclostreptin, the apparent $K_{\mathrm{a}}$ value rose as the temperature increased, and the van't Hoff analysis showed that the binding reaction was dominated by an endothermic, entropic profile. The relatively dominant entropy effect associated with the binding of cyclostreptin to microtubules is probably due to the paucity of substituents on the hydrophobic core that are able to form $\mathrm{H}$-bonds with the binding site or solvent.

We also examined inhibition by cyclostreptin, paclitaxel, and docetaxel of binding of Flutax-2 to microtubules at 4 ${ }^{\circ} \mathrm{C}$. These studies yielded apparent $K_{\mathrm{a}}$ values that, when compared with the $35^{\circ} \mathrm{C}$ values, were little changed for the taxoids but more than 60 -fold lower for cyclostreptin. The inactivity of cyclostreptin at lower temperatures is therefore understandable.

The molecular modeling studies allow us to rationalize these temperature differences and have implications regarding the conformational disposition of the S9-S10 loop of $\beta$-tubulin (see Figure 10). The difference in the abilities to inhibit binding of Flutax-2 to polymer as a function of temperature probably results from the stronger ability of taxoids, as well as epothilones, to form $\mathrm{H}$-bonds with multiple amino acid residues of $\beta$-tubulin. Cyclostreptin can form $\mathrm{H}$-bonds only along the $\mathrm{C}-1-\mathrm{C}-6-\mathrm{C}-8$ axis, while taxoids and epothilones (19) can form H-bonds in many directions. Thus, the latter compounds can have hydrophilic interactions, either directly or through water bridges, with amino acid side chains of the $\mathrm{H} 1$ and $\mathrm{H} 7$ helices and of the M and S9-S10 loops. Cyclostreptin is limited to forming H-bonds with the Arg-367 and Gly-368 carbonyl groups of the S9-S10 loop and possibly with Thr-274 of the M loop.

Thus, a plausible explanation for the enhanced affinity of cyclostreptin for tubulin polymer at higher temperatures is that as the temperature increases there should be a concomitant increase in possible conformations of the S9-S10 and $\mathrm{M}$ loops. The correct spatial disposition for $\mathrm{H}$-bond formation by Arg-367, Gly-368, and Thr-274 with cyclostreptin should occur more frequently. Taxoids and epothilones, however, are able to form more H-bonds, as well as favorable hydrophobic interactions, representing more enthalpic and entropic interactions, respectively, with residues of the H1 and $\mathrm{H} 7$ helices as well as the S9-S10 and M loops. Since there is limited conformational freedom in the amino acid side chains of helices, the binding of taxoids and epothilones should be less sensitive to temperature changes.

The molecular model of cyclostreptin bound in the taxoid site is also consistent with the compound's reduced activity in the cell lines with amino acid changes in $\beta$-tubulin. The phenyl side chain of Phe-270 forms a hydrophobic contact in the model with the $\mathrm{C}$ ring of cyclostreptin, so changing this residue to valine (1A9PTX10) would change the solvent availability and exert an entropic penalty for the binding of cyclostreptin. In the 1A9PTX22 line, Ala-364, which is in the S9-S10 loop, is changed to threonine. This may alter the loop's conformation enough to reduce its number of postulated $\mathrm{H}$-bond interactions with the $\mathrm{C}-1$ carbonyl oxygen atom and/or the two hydroxyl groups of cyclostreptin. The change of Thr-274 to isoleucine (1A9A8) occurs in the M loop. Our model proposes that hydrophobic interactions between cyclostreptin and the $\mathrm{M}$ loop are important for binding the compound. A water-bridged H-bond may form between the Thr-274 hydroxyl and the C-1 carbonyl oxygen atom, since the distance between the oxygen atoms is only $5.13 \AA$ in our model. Changing residue 274 to isoleucine would eliminate this bond, accounting for the reduced sensitivity of the 1A9A8 line to cyclostreptin.

Our findings with glutaraldehyde-fixed microtubules do not explain the reduced activity of cyclostreptin in the absence of MAPs or GTP at higher temperatures. There is also a contradiction between the weakened ability of cyclostreptin to bind to microtubules at $4{ }^{\circ} \mathrm{C}$, as revealed with Flutax-2, and the stable turbidity reading following assembly when the temperature was returned to $0{ }^{\circ} \mathrm{C}$. The latter result implies that, once bound to polymer, cyclostreptin will not dissociate, in contrast to the equilibrium observed with Flutax-2.

The modeling observations provide insight into this paradox. The limited ability of cyclostreptin to form H-bonds at the taxoid site, requiring specific conformations of the S9-S10 and M loops for H-bonding to occur, could account for poor binding at lower temperatures. Once bound, its large hydrocarbon core stabilizes the M loop through hydrophobic collapse with the side chains of Ala-231, Phe-228, and leucines $215,228,273$, and 369 . This extensive hydrophobic complementarity does not occur with taxoids and epothilones and should contribute to a stable interaction of cyclostreptin with tubulin polymer. We also examined possible binding of taxoids or cyclostreptin in the model of tubulin complexed with a stathmin fragment and a colchicinoid (45), but there was no adequate binding site for either taxoids or cyclostreptin where these compounds bind in polymer $(19,21)$.

Other explanations for the difference in temperature effects can be found in the reaction conditions, including, first, the trivial possibility that significantly higher tubulin and compound concentrations were used in the assembly experiments. Second, the assembly reactions included MAPs, which were absent from the Flutax-2 system. MAPs could impede dissociation of cyclostreptin from taxoid sites throughout the polymer.

Third, MAPs might prevent dissociation of cyclostreptin from binding sites at microtubule ends. This could make the polymer resistant to cold-induced disassembly. Paclitaxel polymer appears to disassemble by an end-directed mechanism, with concordant reduction in microtubule lengths and polymer mass at $0{ }^{\circ} \mathrm{C}(46)$. 
Fourth, there may be a conformational change in the tubulin dimer following assembly. Dimers in the glutaraldehyde-treated microtubules used in the Flutax-2 studies, while able to bind cyclostreptin, have probably lost conformational flexibility. Untreated tubulin could trap cyclostreptin following binding of the compound by a conformational change.

In summary, cyclostreptin is a structurally complex molecule that binds in the taxoid site of tubulin polymer, and the binding reaction has unusual properties. Despite a high affinity for the taxoid site at higher temperatures, cyclostreptin is deficient in its ability to enhance tubulin assembly. This appears to derive in part from a weakened ability to hypernucleate assembly and from a markedly reduced affinity for the taxoid site at lower temperatures as compared with taxoids and epothilones (34). Despite this reduced affinity for binding directly to polymer at low temperatures, when cyclostreptin induces polymerization at warmer temperatures the resultant microtubules appear to be more cold stable than paclitaxel-induced polymer. $\mathrm{Cy}$ clostreptin has effects on cells that differ little from those observed with paclitaxel, and it loses less activity than paclitaxel or epothilone A in a series of cell lines resistant to these compounds as a consequence of mutations in a $\beta$-tubulin gene.

\section{ACKNOWLEDGMENT}

We acknowledge Prof. J. M. Andreu for discussions and Matadero Madrid Norte S.A. and José Luis Gancedo S. L. for providing the calf brains from which the tubulin used in the Flutax-2 studies was purified.

\section{REFERENCES}

1. Wilson, L., and Jordan, M. A. (1995) Microtubule dynamics: Taking aim at a moving target, Chem. Biol. 2, 569-573.

2. Schiff, P. B., Fant, J., and Horwitz, S. B. (1979) Promotion of microtubule assembly in vitro by taxol, Nature 277, 665-667.

3. Bollag, D. M., McQueney, P. A., Zhu, J., Hensens, O., Koupal, L., Liesch, J., Goetz, M., Lazarides, E., and Woods, C. M. (1995) Epothilones, a new class of microtubule-stabilizing agents with a taxol-like mechanism of action, Cancer Res. 55, 2325-2333.

4. Ter Haar, E., Kowalski, R. J., Hamel, E., Lin, C. M., Longley, R. E., Gunasekera, S. P., Rosenkranz, H. S., and Day, B. W. (1996) Discodermolide, a cytotoxic marine agent that stabilizes microtubules more potently than taxol, Biochemistry 35, 243-250.

5. Ciomei, M., Albanese, C., Pastori, W., Grandi, M., Pietra, F., D’Ambrosio, M., Guerriero, A., and Battistini, C. (1997) Sarcodictyins: A new class of marine derivatives with mode of action similar to Taxol, Proc. Am. Assoc. Cancer Res. 38, 5.

6. Long, B. H., Carboni, J. M., Wasserman, A. J., Cornell, L. A., Casazza, A. M., Jensen, P. R., Lindel, T., Fenical, W., and Fairchild, C. R. (1998) Eleutherobin, a novel cytotoxic agent that induces tubulin polymerization, is similar to paclitaxel (Taxol), Cancer Res. 58, 1111-1115.

7. Mooberry, S. L., Tien, G., Hernandez, A. H., Plubrukarn, A., and Davidson, B. S. (1999) Laulimalide and isolaulimalide, new paclitaxel-like microtubule-stabilizing agents, Cancer Res. 59, 653-660.

8. Sato, B., Muramatsu, H., Miyauchi, M., Hori, Y., Taskase, S., Hino, M., Hashimoto, S., and Terano, H. (2000) A new antimitotic substance, FR182877: I. Taxonomy, fermentation, isolation, physico-chemical properites and biological activities, J. Antibiot. $53,123-130$.

9. Sato, B., Nakajima, H., Hori, Y., Hino, M., Hashimoto, S., and Terano, H. (2000) A new antimitotic substance, FR182877: II. The mechanism of action, J. Antibiot. 53, 204-206.

10. Yoshimura, S., Sato, B., Kinoshita, T., Takase, S., and Terano, H. (2000) A new antimitotic substance, FR182877: III. Structure determination, J. Antibiot. 53, 615-622 [(2002) J. Antibiot. 55, p C-1 (errata)].

11. Hood, K. A., West, L. M., Rouwé, B., Northcote, P. T., Berridge, M. V., Wakefield, S. J., and Miller, J. H. (2002) Peloruside A, a novel antimitotic agent with paclitaxel-like microtubule-stabilizing activity, Cancer Res. 62, 3356-3360.

12. Isbrucker, R. A., Cummins, J., Pomponi, S. A., Longley, R. E., and Wright, A. E. (2003) Tubulin polymerizing activity of dictyostatin-1, a polyketide of marine sponge origin, Biochem. Pharmacol. 66, 75-82.

13. Rowinsky, E. K., and Donehower, R. C. (1995) Paclitaxel (Taxol), N. Engl. J. Med. 332, 1004-1014.

14. Cortes, J. E., and Pazdur, R. (1995) Docetaxel, J. Clin. Oncol. 13, 2643-2655.

15. Vosburg, D. A., Vanderwal, C. D., and Sorensen, E. J. (2002) A synthesis of (+)-FR182877, featuring tandem transannular DielsAlder reactions inspired by a postulated biogenesis, J. Am. Chem. Soc. 124, 4552-4553.

16. Vanderwal, C. D., Vosburg, D. A., Weiler, S., and Sorensen, E. J. (2003) An enantioselective synthesis of FR182877 provides a chemical rationalization of its structure and affords multigram quantities of its direct precursor, J. Am. Chem. Soc. 125, 53935407.

17. Evans, D. A., and Starr, J. T. (2002) A cascade cycloaddition strategy leading to the total synthesis of (-)-FR182877, Angew. Chem., Int. Ed. 41, 1787-1790.

18. Giannakakou, P., Sackett, D. L., Kang, Y.-K., Zhan, Z., Buters, J. T. M., Fojo, T., and Poruchynsky, M. S. (1997) Paclitaxel resistant human ovarian cancer cells have mutant $\beta$-tubulins that exhibit impaired paclitaxel driven polymerization, J. Biol. Chem. $272,17118-17125$.

19. Giannakakou, P., Gussio, R., Nogales, E., Downing, K. H., Zaharevitz, D., Bollbuck, B., Poy, G., Sackett, D., Nicolaou, K. C., and Fojo, T. (2000) A common pharmacophore for epothilones and taxanes: Molecular basis for drug resistance conferred by tubulin mutations in human cancer cells, Proc. Natl. Acad. Sci. U.S.A. 97, 2904-2909.

20. Hamel, E., Sackett, D. L., Vourloumis, D., and Nicolaou, K. C. (1999) The coral-derived natural products eleutherobin and sarcodictyins A and B: Effects on the assembly of purified tubulin with and without microtubule-associated proteins and binding at the polymer taxoid site, Biochemistry 38, 5490-5498.

21. Nogales, E., Wolf, S. G., and Downing, K. H. (1998) Structure of the $\alpha \beta$ tubulin dimer by electron crystallography, Nature 391, 199-203.

22. Hamel, E., and Lin, C. M. (1984) Separation of active tubulin and microtubule-associated proteins by ultracentrifugation and isolation of a component causing the formation of microtubule bundles, Biochemistry 23, 4173-4184.

23. Grover, S., and Hamel, E. (1994) The magnesium-GTP interaction in microtubule assembly, Eur. J. Biochem. 222, 163-172.

24. Souto, A. A., Ancuña, A. U., Andreu, J. M., Barasoain, I., Abal, M., and Amat-Guerri, F. (1995) New fluorescent water-soluble taxol derivatives, Angew. Chem., Int. Ed. Engl. 34, 27102712.

25. Andreu, J. M., Perez-Ramirez, B., Gorbunoff, M. J., Ayala, D., and Timasheff, S. N. (1998) Role of the colchicine A ring and its methoxy groups in the binding to tubulin and microtubule inhibition, Biochemistry 37, 8356-8368.

26. Behrens, B. C., Hamilton, T. C., Masuda, H., Grotzinger, K. R., Whang-Peng, J., Louie, K. G., Knutsen, T., McKoy, W. M., Young, R. C., and Ozols, R. F. (1987) Characterization of a cisdiamminedichloroplatinum(II)-resistant human ovarian cancer cell line and its use in evaluation of platinum analogues, Cancer Res. 47, 414-418.

27. Skehan, P., Storeng, R., Scudiero, D., Monks, A., McMahon, J., Vistica, D., Warren, J. T., Bokesch, H., Kenney, S., and Boyd, M. R. (1990) New colorimetric cytotoxicity assay for anticancerdrug screening, J. Natl. Cancer Inst. 82, 1107-1112.

28. Terry, B. J., and Purich, D. L. (1980) Assembly and disassembly properties of microtubules formed in the presence of GTP, 5' guanylyl imidodiphosphate, and $5^{\prime}$-guanylyl methylenediphosphate, J. Biol. Chem. 255, 10532-10536.

29. Dixon, M., Webb, E. C., Thorne, C. J. R., and Tipton, K. F. (1979) Enzymes, 3rd ed., Academic Press, New York.

30. Díaz, J. F., Strobe, R., Engelborghs, Y., Souto, A. A., and Andreu, J. M. (2000) Molecular recognition of taxol by microtubules: Kinetics of binding of fluorescent taxol derivatives to an exposed site, J. Biol. Chem. 275, 26265-26276. 
31. Andreu, J. M., and Barasoain, I. (2001) The interaction of baccatin III with the taxol binding site of microtubules determined by a homogeneous assay with fluorescent taxoid, Biochemistry 40, 11975-11984.

32. Pryor, D. E., O’Brate, A., Bilcer, G., Díaz, J. F., Wang, Y., Wang, Y., Kabaki, M., Jung, M. K., Andreu, J. M., Ghosh, A. K., Giannakakou, P., and Hamel, E. (2002) The microtubule stabilizing agent laulimalide does not bind in the taxoid site, kills cells resistant to paclitaxel and epothilones, and may not require its epoxide moiety for activity, Biochemistry 41, 9109-9115.

33. Nicolaou, K. C., Ritzén, A., Namoto, K., Buey, R. M., Díaz, J. F., Andreu, J. M., Wartmann, M., Altmann, K.-H., O'Brate, A., and Giannakakou, P. (2002) Chemical synthesis and biological evaluation of novel epothilone B and trans-12,13-cyclopropyl epothilone B analogues, Tetrahedron 58, 6413-6432.

34. Buey, R. M., Díaz, J. F., Andreu, J. M., O’Brate, A., Giannakakou, P., Nicolaou, K. C., Sasmal, P. K., Ritzén, A., and Namoto, K. (2004) Interaction of epothilone analogs with the paclitaxel binding site: Relationship between binding affinity, microtubule stabilization, and cytotoxicity, Chem. Biol. 11, 225-236.

35. Hofs, R., Walker, M., and Zeeck, A. (2000) Hexacyclinic acid, a polyketide from Streptomyces with a novel carbon skeleton, Angew. Chem., Int. Ed. 39, 3258-3261.

36. Maple, J. R., Hwang, M.-J., Jalkanen, K. J., Stockfisch, T. P., and Hagler, A. T. (1998) Derivation of class II force fields: V. Quantum force field for amides, peptides, and related compounds, J. Comput. Chem. 19, 430-458.

37. Parness, J., and Horwitz, S. B. (1981) Taxol binds to polymerized tubulin in vitro, J. Cell Biol. 91, 479-487.

38. Takoudju, M., Wright, M., Chenu, J., Guéritte-Voegelein, F., and Guénard, D. (1988) Absence of 7-acetyl taxol binding to unassembled brain tubulin, FEBS Lett. 227, 96-98.

39. Díaz, J. F., Menéndez, M., and Andreu, J. M. (1993) Thermodynamics of ligand-induced assembly of tubulin, Biochemistry 32 10067-10077.
40. Kowalski, R. J., Giannakakou, P., Gunasekera, S. P., Longley, R. E., Day, B. W., and Hamel, E. (1997) The microtubule-stabilizing agent disocodermolide competitively inhibits the binding of paclitaxel (Taxol) to tubulin polymers, enhances tubulin nucleation reactions more potently than paclitaxel, and inhibits the growth of paclitaxel-resistant cells, Mol. Pharmacol. 52, 613-622.

41. Kowalski, R. J., Giannakakou, P., and Hamel, E. (1997) Activities of the microtubule-stabilizing agents epothilones A and B with purified tubulin and in cells resistant to paclitaxel (Taxol), J. Biol. Chem. 272, 2534-2541.

42. Grover, S., Rimoldi, J. R., Molinero, A. A., Chaudhary, A. G. Kingston, D. G. I., and Hamel, E. (1995) Differential effects of paclitaxel (Taxol) analogs modified at positions C-2, C-7, and C-3' on tubulin polymerization and polymer stabilization: Identification of a hyperactive paclitaxel derivative, Biochemistry 34 , 3927-3934.

43. Adam, G. C., Vanderwal, C. D., Sorensen, E. J., and Cravatt, B. F. (2003) (-)-FR182877 is a potent and selective inhibitor of carboxylesterase-1, Angew. Chem., Int. Ed. 42, 5480-5484.

44. Ringel, I., and Horwitz, S. B. (1991) Studies with RP 56976 (taxotere): A semisynthetic analogue of taxol, J. Natl. Cancer Inst. 83, 288-291.

45. Ravelli, R. B. G., Gigant, B., Curmi, P. A., Jourdain, I., Lachkar, S., Sobel, A., and Knossow, M. (2004) Insight into tubulin regulation from a complex with colchicine and a stathmin-like domain, Nature 428, 198-202.

46. Gapud, E. J., Bai, R., Ghosh, A. K., and Hamel, E. (2004) Laulimalide and paclitaxel: A comparison of their effects on tubulin assembly and their synergistic action when present simultaneously, Mol. Pharmacol. 66, 113-121.

47. Muramatsu, H., Miyauchi, M., Sato, B., and Yoshimura, S. (1998) Paper 83: A novel microtubule-stabilizing agent, WS9885B (in Japanese), in 40th Symposium on the Chemistry of Natural Products, pp 487-492, Fukuoka, Japan.

BI050660M 